\title{
LA TENTATIVA DE DELITO COMO HECHO PUNIBLE. UNA APROXIMACIÓN ANALÍTICA*
}

\author{
ATTEMPT AS CRIME. \\ AN ANALYTIC APPROACH
}

\author{
Juan Pablo Mañalich R.**
}

\begin{abstract}
RESUMEN: El artículo propone una concepción de la tentativa de delito, basada en una teoría de las normas de orientación analítica, que identifica el déficit de antinormatividad del comportamiento imputable al autor como su rasgo diferenciador. Semejante "imperfección delictiva" es explicada en el sentido de una falta de plena congruencia performativa entre la configuración objetiva del comportamiento del autor y su valor declarativo. Ello es puesto en relación con el debate acerca del problema del "azar moral". El argumento hace reconocible tanto la centralidad del concepto de dolo para la clarificación del concepto de tentativa como la suficiencia del dolo eventual para la sustentación de una imputación a ese título.
\end{abstract}

Palabras clave: Tentativa y consumación, teoría de las normas, dolo.

ABSTRACT: The paper lays down a conception of criminal attempts, grounded upon an analytically oriented theory of norms, which identifies the wrongfulness-deficit of the behavior imputable to the agent as its differentiating mark. Such "offense-imperfection" is explained in the sense of a lack of full performative congruence between the objective configuration of the agent's behavior and its declarative value. This is than related to the debate regarding the problem of "moral luck." The argument soy displayed makes recognizable the centrality of the concept of dolus for the clarification of the concept of attempt, as well as the sufficiency of dolus eventualis for the ascription of an attempt.

Key words: Attempt and consummation, theory of norms, dolus.

\section{LA ANOMALÍA DE LA PUNIBILIDAD DE LA TENTATIVA}

\subsection{INTRODUCCIÓN}

El objetivo de este trabajo consiste en delinear una concepción general de la estructura de la tentativa de delito qua hecho punible, cuyas implicaciones habrán de ser pormenorizadamente desarrolladas en una tríada de trabajos posteriores. La concepción general que aquí se pretende presentar y sustentar, en sus rasgos esenciales, se encuentra construida a sobre la base de la conjunción de las dos siguientes tesis: (1) la específica forma de punibilidad que es característica de la tentativa de delito se encuentra determinada

\footnotetext{
* El presente artículo ha sido elaborado en el marco del Proyecto Fondecyt No 1160147 (regular), del cual el autor es investigador responsable. Agradezco a Alejandra Olave A. por su ayuda en la revisión del texto.

** Doctor en derecho, Universidad de Bonn; profesor titular, Departamento de Ciencias Penales, Facultad de Derecho, Universidad de Chile. Dirección postal: Av. Santa María 076, 7520405, Providencia. Dirección electrónica: jpmanalich@derecho.uchile.cl.
} 
por un determinado déficit exhibido por aquello que funge como el objeto de la correspondiente imputación; y (2) este déficit consiste en que la instancia de comportamiento que se imputa a una persona cuando se la hace responsable de una tentativa de delito no ejemplifica las propiedades cuya conjunción es constitutiva del respectivo género de comportamiento antinormativo.

A partir del asentamiento de las premisas teóricas que conducen a tal comprensión de la tentativa punible, que se distingue por eludir el muy improductivo lugar común representado por la dicotomía "objetivismo-subjetivismo", se vuelve posible indagar en algunas de las preguntas de cuya respuesta tradicionalmente se ha ocupado la dogmática de la tentativa, entre las cuales destaca aquella relativa al criterio de imputación subjetiva de cuya satisfacción tendría que depender una fundamentación de responsabilidad jurídicopenal bajo ese mismo título. El aparato teórico así presentado debería lograr, en virtud de su elevado grado de abstracción, hacer conmensurables cánones discursivos y herramientas conceptuales provenientes tanto de la tradición de la dogmática jurídico-penal de influencia alemana, por un lado, como de la elaboración filosófica y doctrinal de los sistemas de derecho penal adscritos a la tradición del common law, por otro ${ }^{2}$.

\subsection{LA FALTA DE ANTINORMATIVIDAD DE LA TENTATIVA DE DELITO}

La fundamentación preliminar de la proposición según la cual la forma de punibilidad propia de una tentativa de delito se caracteriza por un déficit de antinormatividad como su marca distintiva exige poner en relación de dos puntos de vista teóricos que, aun cuando heterogéneos, admiten ser reconstructivamente unificados. Estos dos puntos de vista se corresponden con la perspectiva de análisis que emerge de la adopción de un determinado modelo de teoría de las normas, que hace posible plantear la pregunta por el estatus de una tentativa de delito qua instancia de quebrantamiento de una norma de comportamiento jurídico-penal reforzada, por un lado, y con la perspectiva que emerge de la organización de los presupuestos delictivos de un comportamiento a partir de la identificación del tipo-de-hecho-punible de cuya realización o falta realización a través de ese mismo comportamiento se trata, por otro ${ }^{3}$.

La realización (imputable) del tipo básico de un determinado género delictivo se corresponde con el quebrantamiento (imputable) de la norma "primaria" de comportamiento, susceptible de ser pragmáticamente inferida a partir de la correspondiente norma "secundaria" de sanción, esto es, de aquella cuyo supuesto de hecho (atómico) se identifica con ese mismo tipo de "delito genérico". Esta noción de tipo de delito genérico se obtiene

\footnotetext{
1 A modo de muestra de la pervivencia de la dicotomía en la presentación general de las posiciones en disputa en la dogmática de la tentativa punible, véase Politoff (1999) pp. 106 ss.; Farré Trepat (2011) pp. 5 ss., 14 ss.; WaChter (2015) pp. 9 ss., 35 ss. Para una muy sofisticada reconstrucción diferenciada de "temas subjetivistas" y "temas objetivistas" en el régimen jurídico de la tentativa, véase Duff (1996), pp. 147 ss., 193 ss. Una presentación canónica de la tensión entre las dos orientaciones, en referencia a la dogmática de la tentativa, se encuentra en SPENDEL (1953) pp. 521 ss. Latamente al respecto MAIER (2005) pp. 19 ss.

2 Un esbozo programático de un modelo de "teoría comparativa del hecho punible", así orientado, se encuentra en MaÑalich (2006).

3 Para lo que sigue, véase Mañalich (2014) pp. 17 ss.
} 
de la combinación de un concepto de delito-género à la Binding y un concepto de tipo a la Beling ${ }^{4}$. A través de esta combinación se obtiene una doble modificación recíproca: por una parte, una modificación "belingiana" del concepto de delito-género de Binding, consistente en la exclusión de todos los presupuestos de la imputabilidad del quebrantamiento de la norma de comportamiento respectiva; por otra, una modificación "bindingiana" del concepto de tipo de Beling, consistente en la identificación del tipo con el concepto estricto de tipo-de-delito (Deliktstatbestand), lo cual conlleva una exclusión de los presupuestos de la punibilidad stricto sensu, fijados en el nivel de las normas de sanción, operativos como filtros de significación jurídico-penal del quebrantamiento de una determinada norma de comportamiento.

Tratándose del tipo de un delito comisivo, la norma de comportamiento correspondiente estará constituida por una norma de prohibición; tratándose del tipo de un delito omisivo, por una norma de requerimiento ${ }^{5}$. Una norma de prohibición es una razón autoritativamente perentoria para la omisión de acciones de cierto tipo, en tanto que una norma de requerimiento es una razón autoritativamente perentoria para la ejecución de acciones de cierto tipo ${ }^{6}$. Que una acción cuente como instancia (token) de un tipo (type) de acción, depende de que ella satisfaga la descripción que especifica las propiedades cuya conjunción es constitutiva del correspondiente tipo de acción ${ }^{7}$. Así, si el tipo de acción $\Phi$ se encuentra sometido al operador de la prohibición, y la acción $\varphi$ es una instancia de $\Phi$, entonces $\varphi$ se encuentra prohibida en cuanto subsumible bajo la prohibición de $\Phi$; si $\Phi$, en cambio, se encuentra sometido al operador del requerimiento, y $\varphi$ es una instancia de $\Phi$, entonces $\varphi$ se encuentra requerida en cuanto subsumible bajo el requerimiento de $\Phi$. Sobre esta base, la específica antinormatividad exhibida por un comportamiento con potencial relevancia jurídico-penal tiene que ser entendida como una propiedad superviniente al conjunto de propiedades -en tal medida, "primarias"- que, en cuanto exhibidas por ese mismo comportamiento, determinan que este pueda ser descrito como la no-omisión de una acción prohibida o la no-ejecución de una acción requerida, según corresponda ${ }^{8}$. Esas propie-

\footnotetext{
4 Para la correspondiente noción de delito-género (Gattungsdelikt), véase BINDING (1902) pp. 5 s.; BINDING (1922) p. 190. Por tal cabe entender, extensionalmente, la clase conformada por todas las instancias de quebrantamiento imputable de una y la misma norma de comportamiento. Para el correspondiente concepto de tipo (Tatbestand), véase Beling (1906) pp. 1 ss., 20 ss., 110 ss., quien lo define como el delineamiento (Umriß) abstracto del correspondiente Verbrechenstypus; más claramente todavía BeLING (1930) pp. 14 ss., 17 ss.

5 En lo que se sigue se usará la expresión "norma(s) de requerimiento" como sustituto de la más tradicional expresión "norma(s) de mandato", para neutralizar todo posible resabio imperativista que pudiera estar asociado al uso de esta última expresión.

6 Para una explicación del recurso a la noción de perentoriedad aquí favorecida, véase MaÑALICH (2017).

7 Al respecto y desde perspectivas diferentes, véase Von Wright (1963a) pp. 36 s.; Von Wright (1983) pp. 112 ss.; Goldman (1970) pp. 10 ss.; Moore (1993) pp. 280 ss.

8 Para esta caracterización de la antinormatividad como propiedad superviniente, véase MAÑALICH (2009) pp. 41 ss. Para la fundamentación de la tesis favorable a la identificación negativa del comportamiento antinormativo qua objeto de una posible imputación, sobre la base de la postulación del principio de la "contrafacticidad de la imputación”, véase Mañalich (2014a) pp. 23 ss., 27 s. Debe notarse, adicionalmente, que nada anómalo hay en admitir, entre las posibles propiedades fundantes-de-antinormatividad, propiedades negativas, tal como ello es favorecido por ontologías relativamente tolerantes; véase al respecto ZANGWILL (2011), aun cuando atribuyendo un grado de "realidad mayor", con todo, a las propiedades positivas; también BArON et al. (2013).
} 
dades -en tal medida primarias- a las cuales superviene la antinormatividad del respectivo comportamiento pueden ser denominadas "propiedades fundantes-de-antinormatividad".

Una implicación de esta caracterización de la antinormatividad qua propiedad superviniente consiste en que su predicación de un determinado comportamiento solo es practicable ex post. Por supuesto, esto no significa que, en estos mismos términos, solo ex post resulte antinormativo el comportamiento en cuestión. Pues no es el caso que, como proposición ontológica, una acción se encuentra prohibida o requerida o bien ex ante o bien ex post; antes bien, una acción resulta prohibida o requerida simpliciter, en un sentido que es a la vez objetivo y atemporal ${ }^{9}$, según cuál sea el tipo de acción que ella ejemplifique. El punto es, más bien, que en atención a las restricciones epistémicas que normalmente determinarán la posición de quien haya de comprobar la antinormatividad del respectivo comportamiento, su establecimiento cierto solo será posible ex post, puesto que solo ex post cabrá comprobar, desde esa posición epistémicamente limitada, que el comportamiento en cuestión efectivamente satisface la descripción que especifica las propiedades respectivamente fundantes-de-antinormatividad ${ }^{10}$. Tratándose de normas consistentes en la prohibición o el requerimiento de tipos de "acción causalmente resultativa", ello significa que el establecimiento de la antinormatividad del respectivo comportamiento depende de la comprobación de que ese comportamiento satisface la descripción que le confiere relevancia causal para el acaecimiento del resultado en cuestión, paradigmáticamente en la forma de la no omisión de una acción prohibida en cuanto productiva del resultado, o bien en la forma de la no ejecución de una acción requerida en cuanto impeditiva del resultado ${ }^{11}$.

En contra de esta comprensión del juicio de antinormatividad se ha sostenido que, para evitar la problemática adopción de la perspectiva de un "espíritu cósmico laplaceano" en la que ella descansaría, las normas de prohibición y de requerimiento jurídico-penalmente reforzadas tendrían que entenderse formuladas, más bien, desde un "punto de vista objetivo ex ante", lo cual en particular forzaría a prescindir de toda referencia al condicionamiento (causal) de resultado alguno en la especificación del tipo de acción sometido a la norma respectiva ${ }^{12}$. El problema está en que semejante concepción "perspectivista" se asienta en una confusión sistemática entre el contenido (semántico) y la función (pragmática) de las normas de comportamiento, que a su vez lleva a confundir condiciones de antinormatividad con presupuestos de imputación ${ }^{13}$. Pues de la acertada tematización de la función (pragmática) "de determinación ex ante" de una norma de prohibición o de requerimiento -más precisamente: de su función como razón para la omisión o ejecución de una acción- no se sigue que su contenido (semántico) haya de quedar reducido a una descripción que prescinda de toda especificación de circunstancias cuya efectividad solo pueda ser constatada ex post.

\footnotetext{
9 Véase NAGEL (1979) pp. 30 s.

10 Fundamental KindHÄUSER (1989) pp. 53, 60 ss.; véase también Mañalich (2009) pp. 41 s., 58 s.

11 Véase en detalle Mañalich (2014a) pp. 32 ss.

12 Así Freund (1992) pp. 51 ss., 93 ss. La fundamentación detallada de semejante programa teórico se encuentra en FrISCH (1988) pp. , pp. 33 ss. En contra, véase especialmente BurKhardT (1996) pp. 99 ss.

13 En detalle al respecto Mañalich (2009) pp. 36 ss., 44 ss.
} 
El carácter prohibido o requerido de una acción es necesariamente intensional, esto es, relativo a una determinada descripción ${ }^{14}$, y una de las múltiples maneras de describir una acción es precisamente a través de su puesta en relación con alguna(s) de sus consecuencias $^{15}$. Una norma que prohíbe la producción o que requiere el impedimento de un resultado de cierta índole puede sin más operar como razón para la acción. Pues para ello basta con que la norma especifique las propiedades que ha de exhibir, ex post, una acción para que esta satisfaga la descripción que la convierte en prohibida o requerida, de modo tal que el destinatario situacional de esa misma norma pueda, ex ante, formarse y realizar la intención de omitir o ejecutar tal acción, respectivamente ${ }^{16}$. Por supuesto, es posible que ex ante no haya sido posible prever que la acción a cuya ejecución u omisión el agente se disponía hubiera de llegar a exhibir las propiedades que la convertirían en una acción prohibida o requerida. Pero esta no es una razón para negar el carácter prohibido o requerido de la acción en cuestión, sino más bien para negar que su no-omisión o no-ejecución haya de ser imputada al agente, en el sentido de que este merezca ser personalmente criticado por no haberla omitido o no haberla ejecutado ${ }^{17}$.

Esto supone tomar partido por una caracterización de las normas de comportamiento como "desafíos" o razones externas ${ }^{18}$. De acuerdo con esta concepción, la pregunta de si una persona cuenta con una razón para hacer o no hacer algo, por encontrarse en una situación en la cual la norma resulta aplicable, tiene que ser diferenciada de la pregunta de si esa misma persona o cualquier otra podía situacionalmente responder a la razón que esa misma norma representa, convirtiéndola en un motivo para hacer o no hacer algo ${ }^{19}$. Esto lleva a que Parfit introduzca la siguiente observación: "When people are ignorant, or have false beliefs, they may do what they ought not to do in the decisive-reason-implying sense. But these people may not deserve any criticism, since they may have false beliefs whose truth would have given them sufficient reasons to act as they do. At least in most cases, that is enough to make their act rational'20.

Esto se deja traducir sin más al lenguaje de la teoría de las normas: una persona puede haberse comportado de modo objetivamente contrario a la norma que fungía como razón para omitir la acción por ella ejecutada o bien para ejecutar la acción por ella omitida, pero al mismo tiempo puede no merecer crítica alguna por no haber ajustado su compor-

\footnotetext{
14 Véase Mañalich (2014b) pp. 493 ss.

15 Esto se traduce en que la tradicional distinción entre el resultado y las consecuencias de una acción es asimismo relativa-a-la-descripción; véase MAÑALICH (2014a) pp. 32 ss., 67 ss., con referencias ulteriores.

16 Latamente al respecto Mañalich (2009) pp. 54 ss., 57 ss.

17 Esto conlleva dar razón a Thomson, en contra de Scanlon, en la defensa que la primera hace de la radical objetividad de la "falta de permisibilidad" exhibida por el comportamiento de cuya caracterización deóntica se trata, con total independencia de la posición epistémica en que pudiera encontrarse algún agente a quien ese comportamiento pudiera ser potencialmente adscrito como una "falta". Véase ThOMSON (1990) pp. 170 ss., 227 ss.; al respecto SCANLON (2008) pp. 47 ss.

18 Fundamental Von Wright (1983) pp. 53 ss.; véase Mañalich (2013) pp. 5 ss. Fundacional para la defensa de una concepción internista de las razones para la acción, Williams (1982) pp. 101 ss. Para la defensa de una tesis "externista", véase PARfit (2011) pp. 31 ss., 43 ss., 58 ss.

19 Véase Parfit (2011) p. 34.

20 Parfit (2011) p. 36.
} 
tamiento a esa norma, al no haberse representado estar en una situación en la cual tendría que haber omitido o haber ejecutado la acción en cuestión. El error capital aparece con la pretensión de hacer colapsar la distinción lógica entre ambas cuestiones, de modo tal que cada vez que una persona -ya sea "auténtica" o "promedio" - no haya estado situacionalmente capacitada para transformar la norma en motivo para la omisión o la ejecución de una determinada acción tuviéramos que negar que ella haya contado con una razón para omitir o ejecutar esa misma acción.

Lo crucial de este hallazgo, en lo que aquí interesa, radica en que es posible concebir casos inversos a los precedentemente descritos, esto es, casos en los cuales una persona no se haya comportado de modo objetivamente contrario a la norma en cuestión, mas mereciendo esa persona ser criticada, al haberse representado estar en una situación en la cual, de haber reconocido la norma en cuestión como premisa vinculante, ella tendría que haber omitido o haber ejecutado la acción que en efecto no omitió o no ejecutó. Como observa Scanlon: "When someone is blameworthy, it is generally for doing something that it was wrong. But wrongness and blame can come apart. The blameworthiness of an action depends, in ways wrongness generally does not, on the reasons for which a person acted and the conditions under which he or she did so. [...] It can also make sense to blame a person even when what he did was not impermissible. For example, it can be appropriate to blame a person who has done what in fact was the right thing if he or she did it for an extremely bad reason" 21.

Para adaptar esta observación de Scanlon a la especificidad de la imputación jurídico-penal, es necesario recordar que, en este último contexto, lo que interesa no es la razón que positivamente explica el comportamiento del autor, sino el hecho de que la norma, en cuanto razón externa, no haya sido transformada por aquel en motivo dominante ${ }^{22}$. En tal medida, el punto de Scanlon se deja reformular en el sentido de que hay situaciones en las cuales la falta de transformación de la norma en motivo es reprochable, a pesar de que el comportamiento respectivo no resulta ser antinormativo. Esta es, precisamente, la estructura de los casos en los cuales el comportamiento del autor es imputable a título de tentativa de delito ${ }^{23}$. Y esto vuelve sin más comprensible que en los casos en los cuales la respectiva norma de prohibición o de requerimiento resulta situacionalmente desplazada por alguna norma de permisión o de liberación, que en tal medida funja como una "causa de justificación"24, mas siendo desconocidas por el agente las circunstancias que hacen aplicable esta última norma qua norma excluyente, a aquel también sea imputable una tentativa de aquel delito en que consiste el quebrantamiento de la norma situacionalmente desplazada ${ }^{25}$.

Asúmase que la acción $\phi$ ejemplifica el tipo de acción $\Phi$, sometido al operador de la prohibición, pero al mismo tiempo ejemplifica el tipo de acción $\Psi$, sometido al operador

\footnotetext{
21 SCANLON (2008) pp. $124 \mathrm{~s}$.

22 Véase Mañalich (2013) pp. 7 ss., 12.

23 Mañalich (2009) pp. 57 ss., 61 ss.

24 Para esta caracterización de las normas de permisión y de liberación como normas puramente excluyentes de algún conjunto de normas de prohibición o de requerimiento, véase MAÑALICH (2014b) pp. 474 ss., con referencias ulteriores.

25 Véase KindhäUser (1989) pp. 111 ss.; coincidentemente MoOre (1997) pp. 65 s.
} 
de la permisión, en circunstancias de que la permisión de $\Psi$ resulta ser, en la situación de antinomia en la cual se encuentra el agente A, la norma cuya aplicabilidad es preferente ${ }^{26}$. En tal caso, si A ejecuta $-\mathrm{y}$ en tal medida, no omite- $\phi$, representándose estar en una situación en la cual $\phi$ ejemplifica $\Phi$, mas sin representarse estar en una situación en la cual $\phi$ ejemplifica $\Psi$, entonces A merece ser criticado por no haber omitido $\phi$, a pesar de que su comportamiento no resultaba antinormativo bajo la prohibición de $\Phi$, al encontrarse esta situacionalmente desplazada por la permisión de $\Psi$.

\subsection{La “ATIPICIDAD” DE LA TENTATIVA DE DELITO}

Que las normas de prohibición o de requerimiento cuyo quebrantamiento resulta potencialmente delictivo hayan de ser, en palabras de Binding, "reconstruidas" a través de su inferencia pragmática a partir de algún conjunto de normas de sanción que -en tal medida- las refuerzan ${ }^{27}$, significa que el correspondiente tipo-de-delito solo se ve realizado por un comportamiento que exhiba las propiedades respectivamente fundantes-de-antinormatividad. Lo distintivo de toda tentativa de delito radica, desde este punto de vista, en que el comportamiento que se imputa a su autor es uno que precisamente no exhibe esas propiedades. En esto consiste lo que podemos llamar la "anomalía" de la punibilidad a título de tentativa.

El punto fue cabalmente advertido, con su habitual rigor analítico, por Beling, en su fundamental artículo de 1930, titulado Die Lehre vom Tatbestand. En efecto, Beling llegó a advertir la necesidad de modificar, de un modo para nada insignificante, la definición general del concepto de "crimen" (Verbrechen) alcanzada a través de la investigación plasmada en su monumental Die Lehre vom Verbrechen, de 1906, justamente en lo tocante a la inclusión del adjetivo "típico" o "adecuado-al-tipo" (tatbestandsmäßig) como un componente de esa misma definición. La primera razón esgrimida por Beling, en su artículo de 1930, para revisar la definición así construida radica en que ella no alcanzaría a cubrir las así llamadas "formas de aparición" del hecho punible ${ }^{28}$, entre las cuales figuraría la tentativa, consistentes en formas "dependientes" y "derivativas" de comportamiento punible ${ }^{29}$, que solo se dejarían entender en referencia a la manera en que ellas complementan las formas independientes de comportamiento punible, consistentes en la realización del respectivo tipo (Tatbestand $)^{30}$. Pues como observara Beling, precisamente refutando su anterior afirmación de la adecuación-al-tipo de tales formas de aparición ${ }^{31}$, “'adecuado-al-tipo' significa la ob-

\footnotetext{
26 Respecto del así llamado "modelo de la colisión" y sus implicaciones de cara al problema del "alcance de la exclusión”, en referencia a la colisión entre una o más normas prohibitivas y una o más normas permisivas, véase Mañalich (2014b) pp. 489 ss., 493ss.

27 Binding (1922) p. 50.

28 Una denominación alternativa a esta, igualmente célebre, es la de "causas de extensión" de la pena, favorecida por MAYER (1915) pp. 341 s., quien sostenía, empero, que se trataría de "circunstancias que fundamentan la tipicidad de un comportamiento por la vía de que ellas confieren a los elementos de los delitos individuales una validez que va más allá de su alcance conceptual”.

29 Véase al respecto ya BeLing (1906) pp. 268 ss., 287 ss.

30 Beling (1930) pp. 2, 17 s.

31 Véase Beling (1906) pp. 268 s., aun cuando hablando de una adecuación-al-tipo "modificada”, en cuanto mediada por el esquema definitorio de la respectiva forma de aparición.
} 
jetiva realización del tipo, y las conminaciones de pena contra la tentativa, etc., justamente apuntan, en primera línea, a aquellas acciones en las cuales no puede decirse del autor que él haya realizado el tipo"32.

De ahí que Beling observara que la caracterización de todo hecho punible como consistente en un comportamiento "adecuado-al-tipo" tendría que ser sustituida por su caracterización como un comportamiento en todo caso "referido-al-tipo" (tatbestandsbezogen) $)^{33}$. Tratándose de las ya mencionadas formas de aparición, su referencia-al-tipo estaría dada por el hecho de que el esquema que especifica cada una de ellas, y que en el caso de la tentativa se identificaría con la noción de "inicio de la ejecución”, carecería de autonomía conceptual frente al respectivo tipo: "También las formas de aparición están necesariamente referidas al tipo, [en el sentido de que] los esquemas que se presentan en la forma de los tipos legales también son regulativos para ellas; es solo que ellas no exigen, como sí lo hacen los tipos de delito [Deliktstypen] independientes, una acción adecuada-al-tipo, esto es, la realización del tipo, siendo su referencia-al-tipo más bien de otra índole, determinada por su propio esquema" 34 .

En lo que aquí interesa, el hallazgo de la falta de adecuación-al-tipo de la tentativa llevó a Beling a redefinir completamente la relación en que se encontrarían el concepto de tentativa y la categoría de la así llamada "falta de tipo" (Mangel am Tatbestand) ${ }^{35}$. En contra de la tendencia a identificar esta última categoría con un criterio para la exclusión de la punibilidad de instancias de comportamiento que "ni siquiera" llegarían a ser constitutivas de tentativa, por no exhibir aquellas propiedades de las cuales dependería su carácter delictivo bajo el tipo en cuestión, Beling llegó a advertir que la "falta de tipo" es más bien definitoria del concepto de tentativa, en el sentido de que una tentativa de delito resulta punible a pesar de no conllevar la realización del tipo correspondiente ${ }^{36}$. Esta proposición solo necesita ser cualificada en el sentido de que la determinación conceptual así alcanzada no es stricto sensu pertinente tratándose de casos en los cuales el déficit de antinormatividad del com-

32 BELING (1930) p. 18.

33 BELING (1930) p. 18.

34 BeLing (1930) p. 8. Ello significa que, en los términos favorecidos por Beling -y aquí asumidos- no hay tal cosa como un "tipo" de la tentativa; fundamental al respecto, desde el punto de vista de la diferenciación funcional de las reglas pertenecientes a la parte general y la parte especial, FINCKE (1975) pp. 28 s., 35 ss. En tal medida, las definiciones plasmadas en el art. $7^{\circ}$ del Código Penal (chileno) no contribuyen a la formulación de norma de comportamiento alguna, sino que fijan criterios de imputación propios del "esquema" dependiente de la tentativa (lato sensu).

35 Sobre el problema en la literatura más antigua, véase Binding (1918) pp. 488 ss. Al respecto véase ALWART (1982) pp. 197 ss.; para una panorámica reciente, véase AlCÁCER (2000) pp. 143 ss.; también WACHTER (2015) pp. 42 ss.

36 Beling (1930) p. 20. Véase asimismo Beling (1906) pp. 328 s., observando que, a consecuencia de su regulación “jurídico-positiva” bajo el Código Penal imperial de 1871, la tentativa representaría una excepción a la falta de punibilidad resultante de una "falta de tipo", en la medida en que esa regulación habría determinado que no obstante la constatación de la falta de "culminación" del respectivo hecho punible, para su tipicidad (Typizität) bastaría la existencia de un "comienzo del tipo" (Tatbestandsanfang). No está de más advertir que este último giro idiomático es enteramente incompatible con el enfático rechazo, por parte de Beling, de la confusión entre "tipo" y "realización del tipo"; véase Beling (1906) pp. 111 s., 321 s. Pues en estos términos, lo que puede "comenzar" no es el tipo, sino solo el proceso conducente a su (eventual) realización. 
portamiento imputable qua tentativa resulta de la aplicabilidad preferente de una norma de permisión o de liberación que funge -en vocabulario dogmático- como una causa de justificación, en razón de que la concurrencia de una causa de justificación no compromete -a menos que se adhiera a la teoría de los elementos negativos del tipo- la tipicidad del respectivo comportamiento.

Que una tentativa de delito resulte punible a pesar de que el comportamiento imputable a su autor no realiza el respectivo tipo-de-delito implica, según ya se anticipara, que ese comportamiento queda especificado por una descripción bajo la cual aquel no llega exhibir las propiedades respectivamente fundantes-de-antinormatividad. De ahí que, en estos términos, la tarea de esclarecer la forma de punibilidad que es propia de la tentativa de delito pueda ser reformulada como la de esclarecer el sentido en que una instancia de comportamiento que no exhibe la específica antinormatividad que es propia del correspondiente género delictivo puede resultar, no obstante, imputable en la forma de un quebrantamiento de la norma de comportamiento en cuestión. La clave para ello está en dar cuenta de la manera en que toda tentativa de delito consiste en una instancia de quebrantamiento imperfecto de la norma respectiva. Ello vuelve necesario clarificar, previamente, en qué consiste el proceso de constitución, por vía de imputación, del quebrantamiento de una norma de comportamiento, entendida como una razón para la omisión o la ejecución de acciones de cierto tipo.

\section{LA CONSTITUCIÓN DEL HECHO PUNIBLE POR VÍA DE IMPUTACIÓN}

\subsection{El modelo del Silogismo práCtico}

Puesto que la función práctica de una norma de prohibición o de requerimiento consiste en servir de razón para la omisión o la ejecución de acciones de cierto tipo, su quebrantamiento ha de identificarse con su falta de reconocimiento como razón vinculante, esto es, como razón eficaz para la omisión o la ejecución de la acción en cuestión. Esto se deja reconstruir en los términos del modelo del silogismo práctico, tal como este fuera delineado por Von Wright ${ }^{37}$. Que una norma de prohibición o de requerimiento constituya, respectivamente, una razón para la omisión o la ejecución de alguna acción de cierta clase, significa que esa norma tendría que proveer la premisa mayor de una inferencia práctica, cuya conclusión se corresponda con la omisión o la ejecución de una acción que a su vez ejemplifica un determinado tipo de acción ${ }^{38}$.

En estos términos, el modelo del silogismo práctico ofrece una esquematización de la estructura de fundamentación de un (concreto) deber de abstención -esto es, de omitir una acción- o un concreto deber de acción -esto es, de ejecutar una acción- a partir de una norma (abstracta) de prohibición o de requerimiento que pueda fungir como la premisa mayor de la correspondiente inferencia práctica. Asúmase, a modo de ejemplo, que dos

37 Fundamental Von Wright (1963b) pp. 160 ss.; Von Wright (1971) pp. 96 ss.; Von Wright (1983) pp. 1 ss., 18 ss.; muy de cerca KINDHÄUSER (1980) pp. 146 ss. De especial relevancia para la versión del modelo aquí favorecida, BRANDOM (1994) pp. 245 ss., 249 ss., quien reconoce la plena conclusividad práctica de un silogismo cuya premisa mayor pudiera estar constituida por alguna regla de obligación.

38 Véase Mañalich (2014a) pp. 17 ss., 23 ss., con referencias ulteriores. 
individuos, A y B, se encuentran junto a la orilla de un río de aguas profundas, en circunstancias de que B no sabe nadar. En esta situación, bajo la premisa "mayor" de que (para cualquiera) está prohibido matar a otro ${ }^{39}$, y bajo la premisa "menor" de que la acción consistente en empujar a $\mathrm{B}$ al río condicionará, ceteris paribus, la muerte de $\mathrm{B}$ por inmersión, entonces se sigue la conclusión de que A debe abstenerse de empujar a B al río ${ }^{40}$.

Para que tal patrón de inferencia efectivamente pueda terminar en una conclusión que exhiba la marca de lo que Von Wright denominara una "necesidad práctica subjetiva", ${ }^{41}$ es imprescindible, desde luego, que el argumento se encuentre construido desde la perspectiva del propio agente, esto es: "en primera persona" ${ }^{42}$. Pues solo en este caso podrá su conclusión consistir en la efectiva formación y realización de una intención, lo cual quiere decir: en la omisión o la ejecución intencional de una acción por parte del agente ${ }^{43}$. Pero esto no basta. Pues es asimismo imprescindible que el destinatario de la norma adopte una determinada actitud "crítico-práctica" respecto de esta en cuanto pauta de comportamiento vinculante ${ }^{44}$. Así, el deber de ejecutar u omitir una determinada acción, especificado por la conclusión de una inferencia práctica, cuya premisa mayor esté provista por una norma de prohibición o de requerimiento en cuanto "razón externa", solo exhibirá la marca de la necesidad práctica subjetiva en la medida en que la norma en cuestión sea reconocida por su destinatario como razón para ejecutar u omitir la acción en cuestión.

Así, que una norma exhiba el estatus de una razón "objetivamente existente" significa que su fuerza motivacional como premisa práctica no se encuentra per se asegurada, sino que depende de que esa misma norma sea "subjetivamente reconocida" como tal por su respectivo destinatario. De esto se sigue, a contrario sensu, que el solo hecho de que una determinada acción no haya sido ejecutada o no haya sido omitida en una situación en la cual una norma fundamentaba el deber de ejecutar u omitir tal acción, sirve de base para concluir, en la forma de un argumento ("destructivo") en modus tollendo tollens ${ }^{45}$, que la respectiva inferencia práctica en efecto no tuvo lugar, esto es: que esa norma no llegó a ser subjetivamente reconocida como premisa de un silogismo. Para seguir con el ejemplo ya utilizado previamente: si comprobamos que A efectivamente empujó a $\mathrm{B}$ al río de aguas

\footnotetext{
39 Aquí es fundamental advertir que la "oración deóntica" que especifica la premisa mayor del correspondiente silogismo puede ser interpretada tanto como la formulación de la norma en cuestión cuanto como un enunciado normativo que informa acerca de ella; véase VON WRIGHT (1963a) pp. 93 ss., 100 ss., 104 s.; en detalle MaÑALich (2014b) pp. 485 ss.

40 Acerca de las peculiaridades de los patrones de inferencia práctica de esta índole, véase especialmente VON WRight (1983) pp. 13 ss.

41 Von Wright (1983) pp. 5 ss.

42 Para la distinción entre la construcción de un silogismo práctico en primera y en tercera persona, véase VON Wright (1963b) pp. 166 ss.; Von Wright (1983) pp. 3 ss., 8 s., 19 ss., 24 ss.

43 Véase Von Wright (1983) pp. 4 ss.

44 Véase RAZ (1990) pp. 32 ss., quien caracteriza semejante razón (actitudinalmente revestida) como una "razón operativa", por oposición a una razón puramente "auxiliar".

45 Cuya estructura es la siguiente:

Si (es el caso que) $p$, entonces (es el caso que) $q$;

no (es el caso que) $q$;

entonces, no (es el caso que) $p$.
} 
profundas, en circunstancias de que la acción consistente en empujar a $\mathrm{B}$ al río habría de producir la muerte de $\mathrm{B}$, entonces podemos concluir -a modo de "inferencia destructiva"que A en efecto no extrajo la conclusión que él habría tenido que extraer en caso de haber reconocido la prohibición de matar a otro como premisa de una inferencia práctica, a saber: la conclusión consistente en la omisión (intencional) de esa acción.

\subsection{El DOLO COMO CRITERIO DE EVITABILIDAD INTENCIONAL}

Pero la constatación de este déficit de razonamiento práctico con arreglo a la norma no basta para concluir que a A pueda reprocharse la falta de reconocimiento subjetivo de la norma. Pues es posible, desde ya, que la falta de verificación de la conclusión se explique por la falla de un presupuesto implícito en la presentación del silogismo, de cuya efectividad depende, empero, que la respectiva conclusión se siga con "necesidad práctica subjetiva" a partir de las premisas, a saber: que el destinatario de la norma haya sido físicamente capaz de omitir la acción prohibida, o bien de ejecutar la acción requerida, según corresponda. Por otra parte, es igualmente posible que la falta de verificación de la conclusión del silogismo se explique por el hecho de no sostenerse la premisa menor, construida desde el punto de vista del propio destinatario de la norma. Uno y otro caso resultan equiparables, entonces, en el sentido preciso de que en ambos falla un presupuesto de la capacidad individual de A para omitir intencionalmente (ex ante) una acción que (ex post) habría de ejemplificar el tipo de acción sometido al operador deóntico de la prohibición ${ }^{46}$. Y no estando situacionalmente capacitado el destinatario de una norma de prohibición para omitir la acción prohibida a modo de conclusión de una inferencia práctica, entonces no cabría imputarle el quebrantamiento de la norma a título de una infracción de deber, en la medida en que "deber implica poder": ultra posse nemo obligatur ${ }^{47}$.

Esta última observación puede contribuir a iluminar el problema concerniente a la función desempeñada por el concepto de intención en el contexto de la esquematización silogística de la fundamentación situacional de un deber de abstención o de acción a partir de una norma de prohibición o de requerimiento. Pues toda omisión o ejecución de una acción susceptible de ser efectivamente explicada como guiada por una razón determinada ha de ser identificada, en el contexto de esa misma explicación, bajo una descripción que la hace intencional en referencia a la razón que la ha guiado ${ }^{48}$. La razón para esto se encuentra en el rol distintivamente jugado por las intenciones en el razonamiento práctico. Siguiendo a Bratman, una intención puede ser entendida como un compromiso práctico ${ }^{49}$, esto es, un compromiso que, como sugiere Brandom, puede adquirirse a partir del reconocimiento de alguna razón como título legitimador (entitlement) para la omisión o ejecución de alguna acción $^{50}$. Sobre esta base, la naturaleza práctica de un silogismo -valga la redundancia-

\footnotetext{
46 Lo cual llevaría a descartar una posible imputación "ordinaria” de su quebrantamiento a título de dolo, véase KindHÄUSER (2007) pp. 455 s.; MAÑAlich (2009) pp. 55 s.

47 Véase en detalle MañAlich (2009) pp. 46 ss., 49 ss., con referencias ulteriores.

48 Brandom (1994) pp. 243 ss., 253 s.

49 Véase Bratman (1999) pp. 3 ss., 15 ss., 107 ss.; véase Yaffe (2010) pp. 82 ss.

50 BRANDOM (1994) pp. 253 ss. El carácter auténticamente práctico del compromiso en que consiste una intención puede volver problemática la distinción que Yaffe hace entre las nociones de "compromiso" (com-
} 
práctico admite ser más claramente delineada si recurrimos a la distinción, bien establecida en la filosofía de la acción, entre los conceptos de "intención-en-la-acción", por un lado, e “intención pura", por otro ${ }^{51}$. Pues la marca de la naturaleza práctica de un silogismo genuinamente práctico puede ser identificada con el hecho de que su conclusión no consiste en la formación de una intención "pura", anticipatoriamente referida a la futura ejecución u omisión de alguna acción, sino más bien con la efectiva ejecución u omisión intencional de tal acción ${ }^{52}$.

De esto se sigue, empero, que el concepto de intención no necesita desempeñar función positiva alguna en el juego de lenguaje de la imputación jurídico-penal. Pues mientras la omisión intencional de una acción $\phi$ representaría la conclusión de un silogismo práctico construido a partir de la prohibición de $\Phi$ como razón subjetivamente reconocida como vinculante, el contexto de la imputación del eventual quebrantamiento de esa misma norma está determinado, por el contrario, por el hallazgo de que semejante conclusión práctica en efecto no tuvo lugar. Luego, la operación de la imputación estará motivada por la pregunta de por qué el agente de hecho falló en materializar la conclusión práctica que tendría que haber extraído de haber sido capaz de transformar el reconocimiento de la norma, que contrafácticamente se esperaba de él, en una instancia de comportamiento intencionalmente dirigido. Esto admite formularse como el principio de la "contrafacticidad de la imputación" 53 . Bajo este principio, lo que necesita ser comprobado es si el agente era capaz de "traducir prácticamente" un eventual reconocimiento subjetivo de la prohibición de $\Phi$ en la omisión intencional de $\phi$. Pues si se comprueba que el agente era capaz de omitir intencionalmente $\phi$, a pesar de lo cual efectivamente no omitió $\phi$, entonces podemos concluir -en el modo tollendo tollens- que en efecto él no reconoció la prohibición de $\Phi$ como una razón vinculante.

Ya fue apuntado que, más allá de su componente físico, la capacidad del agente para omitir intencionalmente $\phi$ depende de que él advierta que $\phi$ es una acción que debería, ceteris paribus, ejemplificar el tipo de acción $\Phi$. ¿Pero qué significa "advertir" aquí? Nótese que $\phi$ sea una acción que debería, ceteris paribus, ejemplificar $\Phi$ quiere decir que $\phi$ habría de exhibir, ceteris paribus, aquellas propiedades cuya conjunción es constitutiva de $\Phi$. Entonces, cabe decir que el agente advierte que $\phi$ habrá de exhibir ese conjunto de propiedades si y solo si él predictivamente cree que $\phi$ habrá de exhibir esas mismas propiedades, en circunstancias de que el concepto de creencia predictiva no es más que una especificación técnica del concepto más general de previsión ${ }^{54}$.

mitment) y "guía" (guidance), entendidas como expresivas de dos componentes del concepto de intentar (trying); véase Yaffe (2010) pp. 72 ss., 82 ss. Para una crítica a Yaffe a este respecto, véase Moore (2013) pp. 144 ss.

51 Véase Searle (1983) pp. 83 ss.; Davidson (2001) pp. 83 ss.; Brandom (1994) pp. 256 ss. Fundamental al respecto Bratman (1999) pp. 111 ss., 128 ss. Véase también Moore (2011) pp. 185 ss.

52 Esta tesis encuentra apoyo directo en lo que Pippin aptamente describe como la concepción expresivista de la acción y de la agencia defendida por Hegel; véase PIPPIN (2008) pp. 147 ss.

$53 \mathrm{Al}$ respecto Mañalich (2013) pp. 7 ss.

54 Véase Hart (1968) pp. 116 ss.; Moore (1997) pp. 409 ss. En general acerca del concepto de predicción y sus usos distintivos, véase Bunge (1999) pp. 224 ss. 
Por supuesto, esto no zanja la muy difícil pregunta acerca del grado preciso en el cual el agente tiene que creer que $\phi$ habrá de ejemplificar el conjunto relevante de propiedades respectivamente fundantes-de-antinormatividad. La consideración crucial aquí, sin embargo, es que esta es una pregunta irreductiblemente normativa ${ }^{55}$. Pues la respuesta depende de la medida en que puede esperarse que el agente despliegue sus propias capacidades en pos de omitir $\phi$. Uno podría concebir, desde luego, que un sistema jurídico cualificara la creencia del potencial autor, en el sentido de que él tuviera que tener por cierto que su comportamiento habrá de ejemplificar esas mismas propiedades. La generalidad de los sistemas jurídicos, empero, tiende a exigir menos que eso. Bajo regímenes jurídicos adscritos a la tradición del derecho europeo continental, una creencia cualificada por un cierto grado de probabilidad es suficiente para una adscripción de dolo eventual. Siguiendo a este respecto a Kindhäuser, el grado de probabilidad relevante para la modulación de la representación del agente tiene que ser determinado a través de una apelación al estándar (contrafáctico) de una persona racional y razonable que practica la fidelidad al derecho ${ }^{56}$. Lo cual significa: si el agente ejecuta $\phi$ creyendo que $\phi$, con un cierto grado de probabilidad, habrá de exhibir las propiedades que harían de $\phi$ una instancia de $\Phi$, en circunstancias de que, sobre la base de esa misma creencia, una persona fiel a derecho habría intencionalmente omitido $\phi$, entonces al agente será imputable la no-omisión de $\phi$ como infracción de deber. En tal medida, la noción aquí relevante de probabilidad es de naturaleza irreductiblemente práctica ${ }^{57}$. Pues ella concierne a la determinación del grado de fuerza asertiva que ha de acompañar a la predicción de que el comportamiento exhibirá las propiedades respectivamente fundamentes-de-antinormatividad, para que esta predicción resulte decisoriamente relevante ${ }^{58}$. desde el punto de vista de una persona que practica la fidelidad al derecho, para la evitación de la respectiva instancia de comportamiento antinormativo.

La versión más viable de semejante concepción de la imputación subjetiva descansa en el recurso a algún conjunto de así llamados "indicadores" de dolo eventual. Estos indicadores consisten en descriptores (doctrinal y jurisprudencialmente) codificados de síndromes de riesgo ${ }^{59}$, en términos tales que el riesgo relevante ha de ser entendido como la posibili-

\footnotetext{
55 Para una contraposición de concepciones psicológicas y concepciones normativas en lo tocante al problema de la determinación del dolo, fundamental Ragués (1999) pp. 189 ss., 205 ss., 275 ss.

56 KindHÄUSER (2007) pp. 456 s., 466 s. La apelación al estándar de una persona "racional y razonable" admite ser ulteriormente precisada adoptando el "enfoque disposicional" elaborado por Stark para dar cuenta de la praxis de adscripción de la correspondiente creencia de la existencia del riesgo, que descansa en la consideración de que la adscripción de una creencia a una persona solo puede ser inteligiblemente explicada en términos de "la coherencia de las disposiciones de un agente con un 'estereotipo disposicional", entendido este como un conjunto de disposiciones a las cuales, desde el punto de vista de las personas comunes y corrientes, se esperaría que se conformen los agentes que tienen la creencia particular en cuestión”; así STARK (2016) pp. 103 ss.

57 La noción aquí relevante de probabilidad debe ser especificada como la probabilidad de que una determinada oración asertiva sea verdadera, considerada desde el punto de vista del propio agente, lo cual determina el carácter práctico, y no teórico, de la noción en cuestión. Fundamental a este respecto Toulmin (2003) pp. 41 ss. 82 ss.; véase también STUCKEnBerg (2007) pp. 289 ss.

58 Acerca de la función del operador "probable (que p)" como dispositivo de "modalización” de predicciones, véase especialmente Toulmin (2003) pp. 44 ss.

59 Acerca de cómo la adscripción de creencias y otras actitudes doxásticas con relevancia para la imputación jurídico-penal descansa en criterios ("públicos") concernientes al comportamiento lingüístico y extralingüístico del sujeto a quien ellas son adscritas, véase Pardo y Paterson (2013) pp. 130 ss., 138 ss.
} 
dad o chance de que la específica forma de comportamiento antinormativo se vea realizada por el comportamiento del agente ${ }^{60}$. En tal medida, el dolo eventual, en cuanto forma básica de dolo, se deja entender como nada más y nada menos que la conciencia de la adopción del riesgo en cuestión ${ }^{61}$. Esto vuelve prima facie conmensurables las condiciones de las cuales depende una adscripción de dolo eventual con aquellas de las cuales depende, al interior de la tradición del derecho penal angloamericano, una adscripción de recklessness ${ }^{62}$ entendida como la creencia, susceptible de ser correctamente adscrita al agente, de que existe un específico riesgo de que su comportamiento llegue a exhibir las propiedades que objetivamente lo harían jurídicamente incorrecto ${ }^{63}$.

Pero es crucial hacer explícito un aspecto ulterior de la adscripción de una creencia fundante-de-dolo, que suele ser pasado por alto. Se trata de lo que, siguiendo a Von Wright, cabría llamar el aspecto "situacional" de la creencia predictiva en cuestión, cuyo contexto ha de estar constituido por una ocasión que provea la correspondiente "oportunidad-para-la-acción”, esto es, la oportunidad para omitir o ejecutar la acción en cuestión ${ }^{64}$. La marca de éxito de una acción puede ser identificada con el acaecimiento -si la acción es de tipo productivo o destructivo- o el no-acaecimiento -si lo es de tipo preservativo o preventivo- de un cierto cambio, en tanto que tal resultado ("positivo" o "negativo") sea condicionado por la acción en cuestión ${ }^{65}$. Pues solo entonces cabrá decir que la acción particular de que se trata ejemplifica el correspondiente tipo de acción. De esto se sigue que la correspondiente "oportunidad-para-la-acción" estará constituida por una situación en la cual sea (lógicamente) posible condicionar el acaecimiento o el no-acaecimiento del cambio respectivo. Con ello, la creencia predictiva fundante-de-dolo se identifica con la creencia de que se dan las circunstancias que constituyen la situación que provee la correspondiente oportunidad para omitir o ejecutar una acción que haya de llegar a ejemplificar el tipo de acción sometido a prohibición o a requerimiento.

\footnotetext{
60 KindhäUser (2007) pp. 464 ss.; al respecto también Puppe (2011) pp. 32 ss., quien acertadamente enfatiza que la racionalidad de la aplicación de semejantes indicadores depende, sin embargo, de que ellos queden determinados por la definición (irreductiblemente normativa) del concepto de dolo (eventual), esto es, de aquello de lo cual aquellos han de ser indicativos.

${ }_{61}$ Puppe (1991) pp. 14 ss. Puesto que las circunstancias constitutivas del correspondiente "síndrome de riesgo" no necesitan ser efectivas para que su representación (por parte del autor) fundamente una imputación a título de dolo, el carácter "referencial" de esa misma representación se corresponde exactamente con aquello que en la filosofía de la mente -a partir de la obra de Franz Brentano- se conoce como la "intencionalidad" de determinados estados mentales. Véase al respecto, y desde perspectivas parcialmente divergentes, DennetT (1969) pp. 19 ss.; Searle (1983) pp. 6 ss.; Searle (2004) pp. 112 ss.; Brandom (1994) pp. 67 ss. Por ello, y en contra de lo sostenido por Pérez Barberá (2010) pp. 813 s., del acertado rechazo de una conceptualización del dolo como un "estado mental", en atención a que por "dolo" ha de entenderse, más bien, un título de imputación normativamente determinado, no se sigue que el concepto de dolo deje de ser un "concepto referencial" para ser, en cambio, un "concepto de referencia". Pues en cuanto título de imputación, el dolo se construye sobre la base de criterios que conciernen, en parte al menos, a la adscripción de actitudes proposicionales cuyo contenido representacional exhibe la "referencialidad" propia de todo estado intencional.

62 Véase Hart (1968) pp. 119 ss.; Duff (1990) pp. 139 ss.; Robinson (1997) pp. 42 ss. Al respecto STUCKENBERG (2007) pp. 311 ss.

63 Fundamental Stark (2016) pp. 90 ss.

64 Von Wright (1963a) p. 37.

65 VON WRight (1963a) pp. 42 ss.
} 


\section{LA TENTATIVA DE DELITO COMO HECHO PUNIBLE}

\subsection{El Delito tentado COMO Delito “imperfecto"}

Hasta aquí no se ha hecho todavía referencia a la cuestión concerniente al carácter consumado o tentado del delito cuyos pasos de constitución, por vía de imputación, pueden ser hechos explícitos a través del enfoque silogístico precedentemente presentado. En términos de ese mismo enfoque, la consumación de un delito consiste en el hecho de que el potencial autor no omitió o no ejecutó una acción que ejemplifica las propiedades cuya conjunción es constitutiva del tipo de acción sometido a una norma de prohibición o de requerimiento situacionalmente aplicable. Con ello, el concepto de consumación constituye una categoría concerniente al tipo-de-acción de cuya ejemplificación o falta de ejemplificación se trata ${ }^{66}$, en cuanto concepto que expresa la satisfacción de la descripción que especifica ese mismo tipo de acción.

De esto se sigue que la distinción entre un delito consumado y un delito tentado no puede ser adecuadamente entendida como una distinción entre un delito completo y uno incompleto. Pues la noción de completitud tiene que ser referida a algún proceso que se inicia en algún punto de tiempo y que concluye en algún otro punto de tiempo. En el presente contexto, ello solo puede ser significativamente predicado del proceso consistente en la ejecución de una acción particular, que comenzará en algún momento y se extinguirá en otro momento, en circunstancias de que este último punto de tiempo es aquel en el cual la ejecución de la acción, en caso de no verse interrumpida, se encontrará completa. En contraste con la categoría de consumación, entonces, la de completitud se encuentra referida a alguna instancia de acción particular, puesto que concierne al proceso de ejecución de alguna acción ${ }^{67}$, que podrá llegar o no a ejemplificar el tipo de acción correspondiente según cuáles sean las descripciones que lleguen a ser verdaderas de esa misma acción ${ }^{68}$.

Si el problema se plantea en terminología estrictamente jurídico-penal, lo anterior quiere decir que el concepto de consumación es uno cuya aplicación (correcta) expresa la efectiva realización (no-justificada) del respectivo tipo-de-delito a través del comportamiento que funge como objeto de imputación. Puesto que la comprobación de la realización (no justificada) del tipo correspondiente solo puede tener lugar por vía de subsunción ${ }^{69}$, es necesario concluir que por "realización del tipo" debe entenderse, stricto sensu, una relación de satisfacción semántica ${ }^{70}$. En este sentido, hay consumación del delito si y solo si la descripción abstracta en la que consiste el tipo resulta satisfecha por el conjunto de circunstancias

\footnotetext{
66 Moore (1993) pp. 296 s., n. 45; véase también BennetT (1988) pp. 197 s.

67 Esta es una manera en que cabe interpretar lo que dice Von Wright cuando observa que "puede decirse que una acción presupone o requiere alguna actividad", en la medida en que sea el caso que "así como los actos están relacionados con eventos, las actividades están relacionadas con procesos”; así VON WRIGHT (1963a) p. 41.

68 De ahí que la distinción entre completitud e incompletitud solo pueda ser propiamente aplicada al interior de la categoría de la tentativa; véase Duff (1996) pp. 119 s.

69 Véase MAÑalich (2014) con referencias ulteriores.

70 Para esta noción de satisfacción, véase TARSKI (1944) pp. 352 ss. Fundamental para la metodología de la subsunción jurídica, EngIsch (2010) pp. 83 ss., 102 ss.; también Puppe (1979) pp. 22 ss., 77 ss.; y Puppe (2011) pp. 61 ss.
} 
que se identifican con el respectivo objeto de la imputación ${ }^{71}$. Y en estos términos, identificar el concepto de tentativa de delito con el concepto de una "realización parcial" del tipo en cuestión resulta ya analíticamente equívoco, en cuanto indicativo de un error categorial, en la medida en que la comprobación de la realización del tipo tiene el carácter lógico de una operación binaria, que como tal no resiste cuantificación alguna ${ }^{72}$. Lo único que puede verse "realizado parcialmente", en cambio, es el proceso que sirve de sustrato a la eventual realización del tipo.

El punto importante aquí es que el concepto de tentativa pertenece al mismo espacio lógico que el concepto de consumación. Pues la noción de un delito tentado es la noción de un delito no-consumado ${ }^{73}$. Y puesto el concepto de delito consumado especifica el paradigma de comportamiento punible, la marca definitoria de un delito tentado tiene que radicar en aquello que lo convierte en una instancia no-paradigmática de comportamiento punible $^{74}$. ¿Pero qué sustenta el pretendido estatus de la consumación como semejante paradigma? Es posible responder esta pregunta por la vía de redefinir la eventual punibilidad de una instancia cualquiera de comportamiento en el sentido de su eventual significación criminal. Pues es bajo este aspecto que la identificación de la consumación como marca de "perfección delictiva" se vuelve inteligible ${ }^{75}$, de modo tal que podamos identificar la falta de consumación, correspondientemente, como una marca de "imperfección" delictiva ${ }^{76}$.

La significación criminal de un determinado comportamiento puede ser analizada a partir de una caracterización de la respectiva instancia de comportamiento punible como una instancia de comportamiento implícitamente performativo ${ }^{77}$, y más precisamente: como constitutivo de una declaración implícita ${ }^{78}$. Al no omitir $\phi$ cuando la omisión de $\phi$ sería prácticamente necesaria para alguien que subjetivamente reconoce la prohibición de $\Phi$ como razón vinculante, el potencial autor concluyentemente declara, a través de su

71 De ahí que resulte irrenunciable la distinción entre los elementos (conceptuales) que componen el tipo qua descripción abstracta, por un lado, y las circunstancias que, qua componentes de la situación del mundo concretamente dada, realizan esos elementos en un caso particular. Fundamental al respecto Beling (1906) pp. 111 s., $321 \mathrm{s.}$

72 En contra de lo sostenido por Binding (1918) pp. 427 ss., entonces, sub specie realización del tipo la diferencia entre delito consumado y delito tentado no puede entendida como una "diferencia cuantitativa". Fundamental al respecto AlWART (1982) pp. 94 ss., 131 ss.; MAier (2005) pp. 55 ss., quienes acertadamente abogan por la renuncia a la jerga del iter criminis.

73 En tal medida, los conceptos de delito consumado y delito tentado se encuentran en relación de heterogeneidad o mutua exlusión; así ya AlWART (1982) pp. $95 \mathrm{~s}$.

74 Véase Fletcher (1998) pp. 171 ss.; Cahill (2012) pp. 753 ss.

75 Esto no supone desconocer que, a lo largo de la evaluación histórica del pensamiento doctrinal a este respecto, los conceptos de delito consumado y de delito perfecto, no han sido siempre tratados como sinónimos. Véase en particular HruschKa (1999) pp. 237 ss., quien da cuenta de la identificación clásica de la noción de delictum perfectum con la noción de tentativa acabada.

76 Así ya Carrara (1956) pp. 238 ss. A favor de esta misma caracterización de la tentativa de delito, y detalladamente, Jiménez de Asúa (1985) pp. 385 ss.; véase también NovoA (1961) pp. 5 s., aun cuando declarándose escéptico en cuanto al rendimiento teórico de la distinción entre perfección e imperfección delictiva. En la discusión angloamericana, véase BERMAN (2012) pp. 2 ss.

77 El locus classicus para la distinción entre actos de habla explícita e implícitamente performativos sigue siendo Austin (1962) pp. 32 s., 53 ss., 67 ss.

78 Así ya Mañalich (2011) pp. 93 ss. 
comportamiento, que él no reconoce esa misma norma como premisa práctica. Pero es crucial enfatizar el carácter implícito de semejante declaración criminalmente significativa, la cual ha de entenderse materializada en la instancia de comportamiento a través de la cual es expresada la falta de reconocimiento de la norma ${ }^{79}$. Tal declaración será performativamente perfecta si y solo si esa instancia de comportamiento consiste en la no-omisión de una acción que ejemplifique las propiedades que la convierten en una acción sometida a la correspondiente prohibición, esto es, las propiedades que definen el correspondiente género de comportamiento antinormativo. Puesto en términos menos abstractos: la manera performativamente perfecta de no reconocer la prohibición de matar a otro ser humano como razón vinculante es ejecutar -y así: no omitir- una acción que en efecto llega a ser verdaderamente descriptible como consistente en matar a otro ser humano. Pues de esto depende que la configuración objetiva de la instancia de comportamiento en cuestión sea perfectamente congruente con el valor declarativo al cual está asociada su específica significación criminal ${ }^{80}$.

Semejante perfecta congruencia performativa es justamente lo que no es predicable de una instancia de comportamiento criminalmente significativa cuando ella es constitutiva de una tentativa de delito. Pues la esencia de un delito tentado yace en el hecho de que la instancia de comportamiento en cuestión no ejemplifica las propiedades fundantes de la antinormatividad que es definitoria del correspondiente género de delito. Y esto debería volver claro que, en contra del argumento de Yaffe a favor de su así llamado "principio de transferencia" ${ }^{81}$, la declaración de la punibilidad de un delito tentado no puede estar "implícita" en la criminalización de la correspondiente especie de delito consumado. Esto encuentra una confirmación manifiesta bajo cualquier ordenamiento jurídico que restringe la punibilidad de la tentativa a ciertas clases o especies de hecho punible, tal como lo hace el derecho alemán, que fuera del ámbito de los hechos constitutivos de crímenes (Verbrechen) somete la punibilidad de la tentativa a una regla de numerus clausus $^{82}$, pero como también lo hace el derecho chileno, que por defecto excluye la punibilidad de la tentativa de hechos constitutivos de faltas ${ }^{83}$

La imperfecta congruencia performativa que es propia de la tentativa de delito se traduce en que es constitutivo de la estructura de esta que exista una discrepancia entre la actitud subjetiva del potencial autor respecto de la satisfacción, a través de su comportamiento, de la descripción que especifica el género de comportamiento antinormativo, por un lado, y la manera en que el mundo termina siendo con respecto a la satisfacción objetiva

\footnotetext{
79 La razón para esto se halla en que la declaración explícita de un hablante de que él no reconoce una norma razón vinculante carece de aquella naturaleza práctica que pudiera sustentar una interpretación de tal declaración como una contradicción de la norma como una razón vinculante. De ahí que si alguien (meramente) dice no reconocer la prohibición de matar a otro ser humano como razón vinculante, él no está, simplemente por decir eso, fallando en reconocer esa norma como razón vinculante.

80 Para esta tematización del "valor declarativo" del comportamiento punible, véase KINDHÄUSER (1989) pp. 21 s., 41 ss.

81 Véase Yaffe (2010) pp. 21 ss.; Yaffe (2012b) p. 56; Yaffe (2013) pp. 211 s.

82 Según lo establece el apartado $1^{\circ}$ del $\$ 23$ del StGB.

83 Con arreglo a lo dispuesto en el art. 9, en relación con el art. 7, del Código Penal.
} 
de esa misma descripción por parte del comportamiento del potencial autor, por otro. Justamente por ello, ya en 1881 Hälschner podía afirmar que la tentativa conlleva, en todos los casos, "un error del agente" como un elemento conceptual necesario ${ }^{84}$. Esto se ve muy exactamente reflejado en la tesis de Moore, según la cual la punibilidad de un delito tentado se encuentra definida por el hecho de que la "base de merecimiento" queda restringida a una "culpabilidad sin incorrección" (culpability without wrongdoing) ${ }^{85}$. No está de más advertir que exactamente a esta conclusión arribaba Nowakowski, cuando caracterizaba la tentativa de delito como una forma de comportamiento no antijurídica, pero culpable ${ }^{86}$, en el sentido de que aquí "antijurídico no es el querer, sino lo querido. La voluntad del autor se encuentra dirigida a lo antijurídico y puede consiguientemente ser culpable; ella no es, empero, antijurídica” ${ }^{87}$.

Si se advierte que Nowakowski emplea el concepto de antijuridicidad para designar la "contrariedad-a-derecho" eventualmente predicable de la respectiva instancia de comportamiento, entonces es claro que esa noción de antijuridicidad -que ciertamente no coincide con el uso que se hace del término "antijuridicidad" en el marco del discurso dogmático hoy dominante- puede ser tenida por $f$ equivalente, en lo que aquí interesa, a la noción de incorrección a la Moore ${ }^{88}$. Esto se manifiesta en que, de manera enteramente coincidente, Moore sostenga que por "incorrección” debe entenderse aquí una "incorrección en el mundo actual, y no en un mundo posible”, en circunstancias de que el único -y justamente: parasitario- sentido en que cabría hablar de una incorrección como base de merecimiento tratándose de un delito tentado es el sentido en que la culpabilidad en efecto presupone incorrección ${ }^{89}$, a saber, en la forma de una "incorrección en el mundo posible creado por nuestros estados representacionales" 90 .

\subsection{LA NATURALEZA DERIVATIVA DE LA PUNIBILIDAD DE LA TENTATIVA}

El enfoque recién reseñado conduce a una clarificación ulterior del concepto de tentativa de delito. Aun cuando esto ha sido frecuentemente pasado por alto, la satisfacción de las condiciones de punibilidad de una tentativa solo puede ser constatada desde una perspectiva ex post ${ }^{91}$. Pues solo así cabe sostener que la falta de consumación es un elemento constitutivo de la noción de tentativa. Esto fue muy precisamente observado por Hälschner, según quien, dado que, "como tentativa, la acción solo puede aparecer en su relación con aquello que se intentó consumar, [de modo tal que] el concepto de tentativa

\footnotetext{
84 HäLsChNer (1881) p. 344.

85 Moore (1997) pp. 191 ss.

86 NowaKowsKi (1951) pp. 315 s.

87 NowAKOWSKI (1951) p. 316.

88 Que Moore defienda una variante de "legalismo moral", que en efecto lo lleva a subordinar el reconocimiento de la incorrección jurídica de la respectiva forma de comportamiento al reconocimiento de su eventual incorrección moral, no afecta el argumento desarrollado en el texto principal; véase Moore (1997) pp. 639 ss.

89 Esto es pasado por alto por Molina (2001) pp. 764 s. en su crítica a la tesis de NoWAKOWsKI, a quien -siguiendo a Moos- imputa incurrir en una mera "acrobacia de conceptos".

90 Moore (1997) p. 405.

91 Véase empero Donnelly-LaZarov (2015) pp. 135 ss.
} 
solo puede ser negativamente determinado, como la acción que no llevó a la consumación de lo intentado" 92 .

Más allá de que, según se sostendrá más abajo, haya que prescindir de la referencia a aquello que el autor de una tentativa "intenta” consumar, de la observación de Hälschner es posible extraer la proposición de que la significación criminal de una tentativa de delito es derivativa, en el sentido de que su significación criminal solo es derivable de aquella que es propia del correspondiente delito consumado. Esta naturaleza derivativa de la significación criminal de toda tentativa qua tentativa es plenamente advertida por Winch, cuando este observa lo siguiente: "We may of course say that trying to murder a man was something terrible, horrible, wicked; but the possibility of saying this derives from what we can say about the character of the act itself of murdering somebody. This wickedness is, as it were, reflected on to the attempt from what it was an attempt to do"93.

La importancia de esto está en que, sobre tal base, se hace patente que la idea misma de que la noción de un delito tentado pudiera ser entendida como primaria en relación con la noción del correspondiente delito consumado no es más que el resultado de poner de cabeza la verdadera descripción de esa misma relación. La idea de que la noción de un delito tentado sería primaria frente a la de delito consumado conduce a la proposición de que la (eventual) consumación del delito en cuestión solo contaría como la marca de éxito de la tentativa correspondiente ${ }^{94}$. Pero esto es más bien incompatible con la idea de que la noción de que un delito tentado es la noción de un delito "no-exitoso" -por imperfecto-, en circunstancias de que los criterios de éxito, aquí relevantes, son idénticos a las condiciones de las cuales depende la consumación del delito, y no de la tentativa de ese delito. Con ello, la noción misma de una "tentativa consumada" resulta ser, hablando estrictamente, una contradictio in adjecto.

La tesis de que la noción de delito consumado es conceptualmente primaria respecto de la noción de delito tentado encuentra apoyo en el hecho de que, más básicamente, la noción de hacer X sea primaria frente a la noción de intentar hacer $\mathrm{X}^{95}$. Aquí es necesario advertir, empero, que el significado de "tentativa de delito", en cuanto término técnico del discurso jurídico-penal, no queda fijado por el significado que el verbo "intentar" exhibe en el habla cotidiana, de modo tal que no es posible asumir que cada tentativa de delito se sustentaría en el hecho de que el potencial autor haya intentado o (tratado de) ejecutar u omitir alguna acción ${ }^{96}$. Esto no obsta, sin embargo, a que sea reconocible una analogía re-

\footnotetext{
92 HäLsChNer (1881) p. 332.

93 WINCH (1971) p. 220.

94 Así empero Donnelly-Lazarov (2015) pp. 59 ss., 81 ss., distinguiendo entre "tentativas exitosas" y "meras tentativas".

95 Latamente al respecto Duff (1996) pp. 285 ss.

96 Véase Enoch (2012) pp. 32 ss., así como Dahan-Katz (2012) pp. 36 ss., ambos argumentando contra el esfuerzo de Yaffe por determinar el concepto de delito tentado a través de un análisis del concepto de intentar (trying). En contra de la determinación del alcance de la noción jurídica de tentativa (de delito) a través de la apelación al concepto ordinario de intentar (hacer algo), véase ya HeATH (1971) pp. 204 ss. Véase también BERMAN (2012) pp. 3 s., quien resalta la conveniencia teórica de preferir la terminología de "delito imperfecto". En la discusión chilena, la importancia de no asimilar sin más la noción técnica de tentativa a la noción ordinaria de intentar ha sido recientemente advertida por LonDoño (2016) pp. $122 \mathrm{s.}$
} 
levante entre la relación en que se encuentran los conceptos ordinarios de hacer e intentar, por un lado, y la relación en que se encuentran los conceptos técnicos de delito consumado y delito tentado, por otro.

La base para esta analogía no es otra que el hecho de que el concepto ordinario de intentar y el concepto técnico de tentativa muestren un fuerte parentesco en cuanto a la connotación de un cierto fracaso práctico. Por esto cabe entender el hecho de que la situación del mundo inmediatamente posterior a la omisión o la ejecución de la correspondiente acción por parte del agente resulte ser incongruente con alguna actitud proposicional que le atribuimos para fijar la situación del mundo que el propio agente podía esperar obtener a través de su comportamiento. En tal medida, la noción aquí relevante no puede identificarse con la de un fracaso práctico en sentido fuerte, consistente en la falta de realización de alguna intención que pudiera haber dirigido u orientado el comportamiento del agente. Antes bien, se trata de aquí de la noción de un fracaso práctico en sentido débil, consistente en el hecho de que la situación del mundo resultante del comportamiento desplegado por el agente no se ajuste a una expectativa que el agente pudo formarse en razón de la representación de las circunstancias con la que él contaba ${ }^{97}$. Esto quiere decir, más precisamente, que un fracaso práctico en sentido débil es enteramente dependiente de la falta de satisfacción de una actitud proposicional que exhibe una relación de ajuste que va de la mente al mundo, esto es, de una actitud proposicional de naturaleza doxástica: el mundo actual, existente con posterioridad al comportamiento del agente, resulta divergente del mundo posible que el agente se representó como uno que habría podido obtenerse a través de ese comportamiento, con total independencia de que él no haya perseguido (intencionalmente) su obtención.

En relación con el concepto ordinario de intentar, el punto es muy claramente formulado por Von Wright: "It would be a mistake to think that whenever an agent has successfully accomplished an act he has also tried to accomplish it. A similar remark can be made of activity. Normally, when I shut a door or walk or read I cannot be said to try, successfully, to shut the door or to move my legs or to read out the words. To construe every act as a result or consequence of trying to act would be a distortion" 98 . Esto explica que decir de un agente que él o ella ha hecho X de manera no exitosa equivalga a incurrir en una contradictio in adjecto, en tanto que normalmente diríamos que un agente ha intentado hacer X cuando él ha fracasado, justamente, en hacer $\mathrm{X}^{99}$.

\footnotetext{
97 Ello significa que el estándar que hace reconocible un fracaso en sentido débil se identifica con una expectativa que el agente no necesita haberse formado, pero que pudo formarse, en virtud de su correspondiente creencia predictiva. Ciertamente, ello también es el caso cuando el agente tuvo la intención de dar lugar al estado de cosas que no llegó a tener lugar, lo cual determina que todo fracaso práctico en sentido fuerte implique un fracaso práctico en sentido débil, pero no al revés. Véase al respecto Duff (2007) pp. 64 s., ilustrando el sentido que la pregunta “¿por qué lo hiciste?” puede tener tratándose de la producción de efectos colaterales meramente previstos, y no intencionalmente buscados.

98 Von Wright (1963a) p. 51. Véase también Duff (1996) p. 289.

99 Como advierte Duff (1996) p. 289, los otros dos contextos adecuados para hablar sobre "intentar" (trying) se corresponden con situaciones en las cuales es dubitable que el agente pueda hacer X o en las cuales hacer X requiere una alta medida de esfuerzo por parte del agente. Interesantemente, el primer contexto está definido por la incertidumbre de que vaya tenerse éxito en -valga la redundancia- hacer X, mientras el segundo con-
} 
El punto puede ser elucidado todavía más si se considera la analogía que, de acuerdo con Brandom, existe entre las propiedades semánticas de los verbos "intentar" (o "tratar de") y "parecer"100. Lo que Brandom caracteriza como la "desastrosa metafísica de lo mental" implicada en la proposición de que "intentar hacer X" sería primario respecto de "(simplemente) hacer X" es justamente lo que Duff denuncia como el error crucial de la "doctrina del intentar", la cual descansa en una comprensión alienada de nuestra situación como agentes ${ }^{101}$. Tal comprensión alienada, cabe ahora agregar, se halla en el núcleo de una intuición que tiende a encontrar creciente adhesión en un sector de la scholarship angloamericana, cuyo punto de vista resulta indistinguible del que hiciera suyo el así llamado "finalismo radical” en el marco de la dogmática jurídico-penal de cuño alemán ${ }^{102}$. Se trata, en efecto, de la intuición de que la magnitud del reproche y así de la pena merecida por una persona a la cual es imputable alguna tentativa (acabada) de delito debería ser la misma, ceteris paribus, que la merecida por una persona a la cual sea imputable el correspondiente delito consumado ${ }^{103}$. Pues lo contrario supondría -así reza el argumento- hacer depender la medida del reproche merecido por el agente de un factor azaroso, en cuanto situado más allá de su control, referido a la contingencia de que la situación del mundo resultante de su comportamiento sea una que satisfaga la descripción (causal o constitutivamente) compleja que determina en qué consiste la respectiva especie de delito. En esto consiste la denuncia de la irracionalidad pretendidamente implicada en prestar atención a la así llamada "suerte moral" ${ }^{104}$, especificada en este contexto como una suerte en relación con las consecuencias (outcome luck $)^{105}$, a la hora de determinar la magnitud del reproche merecido por una persona en referencia a aquello que le es imputable, denuncia que conduce, en tal medida, a

cierne a la dificultad de la obtención de ese mismo éxito. Al respecto, véase también el pormenorizado análisis, ofrecido en HeAth (1971) pp. 195 ss., de la conexión entre las nociones de tener éxito e intentar.

100 Brandom (1994) pp. 294 s., quien en referencia a la naturaleza parasitaria de la jerga consistente en el uso de "parecer" descansa en el análisis ofrecido por Sellars (1997) pp. 32 ss.

101 Véase al respecto ya Winch (1971) pp. 211 ss.; también Duff (1996) pp. 290 ss.

102 Véase por todos SANCinetTi (1991) pp. 77 ss., 115 ss.; SANCinetTi (1995) pp. 25 ss., 123ss.

103 Son especialmente representativos de este punto de vista los trabajos de AleXANDER y Kessler FerZAN (2009) pp. 171 ss.; Ashworth (1988) pp. 738 ss., 770 ss.; y Feinberg (2003) pp. 77 ss. En la misma dirección ya Hart (1968) pp. 127 ss. Nótese que también se conocen posiciones favorables a la tesis de la equivalencia entre delito consumado y tentativa (acabada) desde el punto de vista del merecimiento de pena exhibido por el autor del respectivo delito, que a la vez niegan, empero, que de ello se siga la solución de una igual magnitud de castigo para uno y otro caso. En este sentido Yaffe (2010) pp. 310 ss., 316 ss.; Donnelly-Lazarov (2015) pp. 169 ss.

104 Fundamental Nagel (1979) pp. 24 ss.; véase también Williams (1981) pp. 20 ss.; así como SCanlon (2008) pp. 125 ss. Latamente al respecto Malamud (2008) pp. 39 ss., 68 ss. Véase también Moore (2007) pp. 211 ss., quien acertadamente problematiza la caracterización de la suerte aquí involucrada como una de índole moral.

105 Siguiendo el seminal análisis ofrecido por NAGEL, es usual diferenciar, como especies del género del azar moral, las siguientes cuatro: (1) la así llamada "suerte constitutiva"; (2) la así llamada "suerte circunstancial" (o "situacional"); (3) la suerte en cuanto a los factores antecedentes; y(4) la suerte en cuanto a las consecuencias. Véase Nagel (1979) pp. 32 ss.; también Malamud (2008) pp. 68 ss., aunque dejando fuera de consideración la tercera de las cuatro especies distinguidas por NAGEL. 
la adopción de la tesis de la equivalencia, también conocida como tesis de la indiferencia, entre consumación y tentativa sub specie merecimiento ${ }^{106}$.

En lo fundamental, se sostiene que esta última proposición encontraría apoyo en la exigencia (pretendidamente) retribucionista de que la magnitud de la pena susceptible de ser impuesta sobre el condenado no quede fijada por factor alguno que no sea el grado de "culpabilidad por la elección" manifestado a través de su comportamiento ${ }^{107}$. Pero no es claro cómo habría que interpretar la preposición "por" en el contexto de esa misma fórmula ${ }^{108}$. Pues esta resulta ser sistemáticamente ambigua respecto de la distinción entre el objeto y la base de una adscripción de responsabilidad ${ }^{109}$. La interpretación que es necesaria para sustentar la tesis de la equivalencia entre consumación y tentativa sub specie merecimiento entiende que la correspondiente "elección" funge como el objeto de la responsabilidad de cuya atribución al potencial autor se trata. Pero esto distorsiona la función que debería ser asignada a la categoría de elección bajo el principio de culpabilidad. Pues es posible entender, más bien, que el término "elección" designa aquí lo que fundamenta la imputación del comportamiento correspondientemente "elegido" por el agente, cuyo alcance queda codeterminado por el conjunto de creencias de las que este haya efectivamente dispuesto ${ }^{110}$. Bajo esta interpretación, entonces, por "elección" cabe entender una base (legitimadora) para la respectiva atribución de responsabilidad, cuyo objeto estará constituido por la instancia de comportamiento en tal medida "elegida" por el agente. Y si bien la elección capaz de fundamentar una adscripción de responsabilidad puede ser exactamente la misma, habiendo o no el delito alcanzado la consumación, la instancia de comportamiento constitutiva del respectivo objeto de la imputación así fundamentada ciertamente será de índole diferente, desde el punto de vista de las descripciones que resultan verdaderas de aquella, según si el delito ha alcanzado o no la consumación. Pues la consumación de un delito no es sino una implicación de que la instancia de comportamiento que se imputa al agente objetivamente exhiba la específica antinormatividad asociada a la realización (no justificada) del correspondiente tipo de delito.

Lo anterior se deja reformular como sigue: mientras la antinormatividad es una categoría concerniente al objeto de la posible imputación, la noción de elección concierne al fundamento -esto es, la base- para tal imputación. Desde este punto de vista, el fundamento para una adscripción de responsabilidad puede ser identificado con la "falta" personal en la que consiste la correspondiente infracción de deber, constituida por vía de

106 Para la primera denominación, véase Donnelly-Lazarov (2015) pp. 156 ss.; para la segunda, Malamud (2008) pp. 39 ss., 77 ss., quien en ciertos contextos la equipara a la de "tesis de la irrelevancia" (de la correspondiente distinción).

107 Véase solo Alexander y Kessler Ferzan (2009) pp. 171 ss.

108 Acertadamente Feinberg (2003) pp. 83 s., aun cuando para alcanzar conclusiones enteramente divergentes a las que se obtienen a través del argumento desarrollado en el texto principal.

109 DAN-Cohen (2002) pp. 202 ss., quien presenta la distinción en términos de la contraposición de una "responsabilidad-objeto" (object-responsibility) y una "responsabilidad-sujeto" (subject-responsibility). Véase también Moore (1997) pp. 36 ss.; y Duff (2007) pp. 82 s.

110 Acerca de la manera en que las creencias correctamente atribuibles a un agente definen el campo de lo elegible para este, véase STARK (2016) pp. 141 ss. 
imputación subjetiva ${ }^{111}$. Con ello, si "antinormatividad" e "infracción de deber" designan dos bases de merecimiento diferentes, puede concluirse que, en cuanto base de merecimiento, la antinormatividad es privativa de la consumación, en tanto que lo que un delito consumado y su correspondiente tentativa comparten, qua base de merecimiento, es la falta personal consistente en la respectiva infracción de deber. En la terminología favorecida por Scanlon, esto quiere decir que mientras el autor de un delito consumado y el autor de la correspondiente tentativa pudieran ser igualmente reprochables, el reproche que cada uno merece es diferente ${ }^{112}$. De este modo, la asimetría entre delito consumado y delito tentado, desde el punto de vista de las bases de merecimiento con pertinencia tratándose de uno y otro, provee de sustento a la tesis de la no-equivalencia entre consumación y tentativa sub specie merecimiento ${ }^{113}$.

\subsection{LA SUFICIENCIA DEL DOLO EVENTUAL}

Tal como ya se estableciera, la esencia de un delito tentado radica en una discrepancia entre la actitud subjetiva del agente acerca de la satisfacción, a través de su comportamiento, de la descripción que especifica las propiedades respectivamente fundantes-deantinormatividad, por una parte, y la manera en que el mundo resulta ser desde el punto de vista de la falta de satisfacción objetiva de esa misma descripción a través del comportamiento del agente, por otra. La pregunta que ahora es necesario responder se refiere a la clase de actitud subjetiva aquí relevante. En este punto es conveniente reparar en que la noción de una falta personal consistente en la respectiva infracción de deber, ya introducida, se deja identificar con lo que Moore entiende por "culpabilidad prima facie", justamente porque tal falta es lo que funge como base para la eventual adscripción de una culpabilidad definitiva ${ }^{114}$. Sobre la base de esta premisa resulta especialmente iluminadora la observación que Moore formula en los siguientes términos: "The key notion is that we are prima facie culpable when we act under a representation of the world that would make our action morally wrongful if the representation were true" 115 .

Que Moore hable aquí de la "incorrección moral" del comportamiento del agente, y no de su antinormatividad en cuanto propiedad jurídicamente constituida, no tiene importancia alguna en el presente contexto ${ }^{116}$. Lo que importa, antes bien, es la consideración de que la actitud que ha de ser reconocible en el agente, y que Moore aptamente tematiza en la forma de una "representación", ha de tener naturaleza doxástica, en el sentido de que ella debe consistir en que el agente tenga algo por verdadero ${ }^{117}$. Ahora bien, la forma básica que puede asumir semejante actitud doxástica es la de una creencia. Esto es de la mayor importancia, en cuanto sugiere que lo que puede contar como el presupuesto mínimamente sufi-

\footnotetext{
111 Para esta noción de "falta", véase Duff (1996) pp. 5 ss., 362 ss.; Brudner (2009) pp. 59 ss., 76 ss.

112 SCANLON (2008) pp. 128 s., 145 s.

113 Véase en particular, y desde perspectivas diferentes, Duff (1996) pp. 327 ss., 350 ss.; Moore (1997) pp. 211 ss., 218 ss.; Brudner (2009) 131ss., 141 ss. Véase también Malamud (2008) pp. 121 ss., 131 ss.

114 Véase Moore (1997) pp. 403 s.

115 Moore (1997) p. 405.

116 Véase, nota 88 anterior.

117 Brandom (1994) pp. 153 ss., 286 ss.
} 
ciente para la constitución de la respectiva falta personal, que a su vez pueda sustentar una atribución de responsabilidad jurídico-penal, es exactamente el mismo tratándose de un posible delito consumado y de un posible delito tentado, a saber: una creencia predictiva cuya adscripción pueda dar lugar a una imputación a título de dolo eventual ${ }^{118}$.

Esta proposición encuentra apoyo inequívoco en la manera en que el modelo del silogismo práctico contribuye a esquematizar las condiciones de constitución, por vía de imputación de una posible tentativa de delito. Como ya se estableciera, la necesidad práctica subjetiva susceptible de ser exhibida por la conclusión de un silogismo práctico depende, entre otros factores, de que la inferencia en cuestión sea construida desde la perspectiva de la primera persona, lo cual significa: desde la perspectiva del propio agente. Y como también lo mostrara Von Wright, una particularidad de semejante silogismo "en primera persona" se halla en que la necesidad práctica de la conclusión no depende de la verdad de la creencia expresada en la premisa menor de la inferencia. En efecto, la falsedad de la creencia con la que cuente el agente deja intacta la necesidad práctica subjetiva de la conclusión $^{119}$. Esto significa que si A erróneamente cree que B es incapaz de nadar por sí mismo, de modo tal que $B$ probablemente moriría por inmersión en caso de ser empujado al río en cuya rivera $B$ se encuentra, entonces $A$ tiene que abstenerse de empujar a $B$ hacia el río, en la medida en que A subjetivamente reconozca la prohibición de matar a otro ser humano como razón vinculante. Si bajo esa misma creencia (errónea) A en efecto empuja a B hacia el río, entonces cabe concluir -en modo tollendo tollens- que A de hecho no reconoció subjetivamente la norma como razón vinculante, con total independencia de que en efecto B no haya resultado muerto en virtud de su capacidad -desconocida para A- de salir nadando del río por sí mismo.

En este último caso, el empujón propinado por $\mathrm{A}$ a $\mathrm{B}$, que hace caer a este hacia el río, cuenta como una instancia de comportamiento susceptible de imputación a A como la infracción de un deber fundamentado por la prohibición del homicidio, a pesar de que la acción ejecutada -y en tal medida: no omitida- por A no llegó a ejemplificar el tipo de acción sometido al operador de la prohibición. Así, en tal caso nos encontramos con la discrepancia ya tematizada, y que es constitutiva de la estructura de toda tentativa, entre la creencia del agente en cuanto a la satisfacción (más o menos probable) de la descripción que especifica el respectivo género de comportamiento antinormativo, por un lado, y la falta de satisfacción objetiva de esa misma descripción a través de su comportamiento, por otro. Precisamente esta discrepancia es lo que define a un caso en el cual del potencial autor cabe decir que está "en falta" por no haber omitido o no haber ejecutado la acción $\phi$, a pesar de que la no-omisión o la no-ejecución de $\phi$ no llega a ejemplificar las propiedades respectivamente fundantes-de-antinormatividad, en razón de que $\phi$ no llega a satisfacer la descripción que haría de $\phi$ una instancia de $\Phi$.

\footnotetext{
118 Sobre el estado de la cuestión en la discusión chilena, de la mano de una muy refinada reconstrucción crítica de la línea jurisprudencial adversa al reconocimiento de la compatibilidad entre tentativa y dolo eventual, véase LoNDOÑo (2016) pp. 101 ss., 111 ss., con múltiples referencias ulteriores.

119 Von Wright (1971) pp. 96 s.; Von Wright (1983) pp. 23 s.
} 
Que tal discrepancia no afecte la fundamentación -silogísticamente reconstruidadel respectivo deber a partir de la norma en cuestión, se sigue del hecho de que, como observara Hart, la técnica de reforzar algún conjunto de normas (primarias) de comportamiento a través de algún conjunto de normas (secundarias) de sanción consiste en que "the members of society are left to discover the rules and conform their behaviour to them; in this sense they 'apply' the rules themselves to themselves" 120.

En este nivel de abstracción, la posición recién delineada parece ser íntegramente expresable a través del recurso al aparato conceptual propuesto por Yaffe, orientado a dar cuenta de las condiciones de punibilidad de un delito tentado. Bajo el enfoque de Yaffe, lo que un delito consumado y su correspondiente tentativa compartirían es un "modo defectuoso de reconocer y responder a razones" ${ }^{121}$. En un principio, Yaffe favorecía el argumento de que semejante concepción solo sería compatible con una definición del concepto jurídico-penal de tentativa en términos de la noción -filosóficamente desentrañada- de "intentar" (trying), de manera tal que un delito tentado solo sería compatible con la satisfacción de una exigencia de intención o propósito en cuanto forma del correspondiente mens rea ${ }^{122}$, exigencia que cabría entender como equivalente a una de dolo directo de primer grado. Más recientemente, sin embargo, Yaffe ha concedido que una concepción de la tentativa de delito construida sobre la noción de "intentar" no se encuentra suficientemente fundamentada en la sola referencia a semejante modo defectuoso de reconocer y responder a razones ${ }^{123}$. Como Yaffe mismo ha observado, este cambio de parecer se explicaría por la eficacia de algunas objeciones dirigidas a tal concepción, que apuntan a que el mismo criterio favorecería, en efecto, un enfoque bajo el cual la previsión de las circunstancias que objetivamente determinarían la ejemplificación del respectivo tipo de delito, susceptible de ser identificada con la noción de recklessness, en el sentido ya cualificado, habría de bastar como presupuesto de la correspondiente falta personal ${ }^{124}$.

Así, y siguiendo una sugerencia efectuada por Duff ${ }^{125}$, Yaffe sostiene ahora que sería necesario incluir una premisa adicional para sustentar la concepción del "intentar", consistente en la exigencia de que las instancias de comportamiento criminal que no alcanzan la consumación de todas formas "comprometan [implicate] los intereses jurídicamente protegidos" que son vulnerados por un delito consumado de la especie respectiva ${ }^{126}$. Esta exigencia ulterior solo sería satisfecha por una tentativa si el concepto de tentativa es definido, en el sentido de la concepción del "intentar", como requiriendo intención o propósito. Pues solo entonces, agrega Yaffe, los delitos tentados resultarían "intencionales bajo una descripción que menciona el delito consumado", de modo tal que "comprometan el conjunto de intereses jurídicamente protegidos que compromete el delito consumado" 127 .

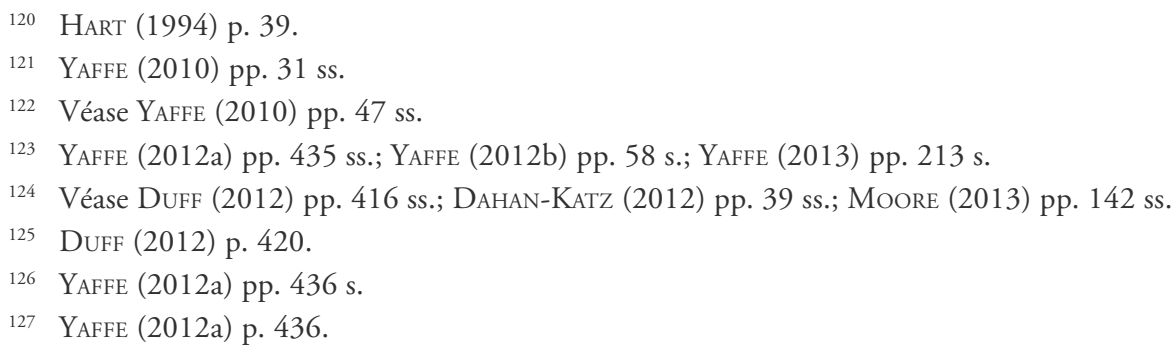


Pero esto es un non sequitur. Pues lo que vincula a una instancia de comportamiento que no alcanza la consumación con la forma de comportamiento antinormativo que se vería realizada en caso de haberse alcanzado la consumación es el contenido representacional de la actitud subjetiva del agente, consistente en una representación de algún conjunto de circunstancias tales que la verdad de esa misma representación implicaría la satisfacción de la descripción que especifica ese mismo género de comportamiento delictivo ${ }^{128}$. Y por supuesto, el hecho de que tal pueda ser el contenido representacional de una posible intención del agente no implica que solo una intención del agente pueda exhibir tal contenido representacional ${ }^{129}$. Antes bien, una actitud doxástica consistente en una creencia predictiva puede tener ese mismo contenido representacional. Y tal creencia predictiva es mínimamente suficiente para adscribir al agente, ceteris paribus, la capacidad de omitir o ejecutar intencionalmente una acción cuya omisión o ejecución habría sido prácticamente necesaria para una persona que hubiese reconocido la respectiva norma de prohibición o de requerimiento como razón vinculante.

\subsection{TRES CONSECUENCIAS}

Sobre la base de la concepción hasta aquí delineada, puede ser pertinente enunciar tres aplicaciones ulteriores del enfoque silogístico para dar cuenta de su rendimiento en pos de la clarificación de algunos problemas que perviven en la dogmática de la tentativa.

El primer problema consiste en determinar el umbral que marca la línea que separa a la tentativa de la mera preparación, respecto de lo cual es usual encontrar algún catálogo de así llamadas "fórmulas" dirigidas a fijar esa línea ${ }^{130}$. En vez de entrar en una indagación pormenorizada en cada una de estas fórmulas, para intentar así dar con aquella sea preferible ante las demás, aquí basta con sugerir que la reconstrucción silogística de la imputación jurídico-penal impone un constreñimiento estructural de la mayor significación en cuanto a las respuestas posibles para esa misma pregunta demarcatoria. Pues ya se estableció que la fundamentación de un deber (de abstención o de acción) a partir de la correspondiente norma de prohibición o de requerimiento involucra un componente situacional, que fija el contenido de la respectiva creencia predictiva de cuya adscripción depende la constitución de la falta personal en cuestión ${ }^{131}$. Esto quiere decir que una imputación a título de tentativa depende de que el agente haya contado con la creencia de encontrarse en una situación que le proveía la correspondiente "oportunidad-para-la-acción”, esto es, una oportunidad para omitir o ejecutar la acción que habría de llegar a exhibir las propiedades respectivamente fundantes de antinormatividad. La consideración crucial a este respecto es

\footnotetext{
128 Moore (1997) p. 413.

129 Véase Moore (1997) pp. 409 ss., quien afirma, empero, que solo una intención, y no así una creencia, sería "suficiente para los niveles más serios de culpabilidad". Pero como acertadamente observa DaHAn-Katz (2012) p. 42, lo que importa es si el modo de reconocimiento de razones reconocible en el comportamiento del hechor "es suficientemente defectuoso para justificar su criminalización como tentativa".

130 En referencia al derecho alemán y español, véase por todos FARRÉ Trepat (2011) pp. 165 ss. En referencia a los sistemas jurídicos de la tradición del common law, véase Duff (1996) pp. 33 ss.; Yaffe (2010) pp. 215 ss., 255 ss.

131 Véase número, 2.2 anterior.
} 
la siguiente: una situación en la cual A tiene una oportunidad para omitir o ejecutar $\phi$ es, en la jerga de Von Wright, lógicamente diferente de una situación en la cual A puede recién generar las condiciones para una futura ejecución u omisión de $\phi$, esto es, una situación en la cual puede recién preparar el futuro quebrantamiento de la norma en cuestión ${ }^{132}$.

Por supuesto, la creencia predictiva del agente puede ser falsa, también con respecto a la existencia objetiva de la situación generadora de la oportunidad-para-la-acción. Desprovista de semejante concreción situacional, sin embargo, la actitud subjetiva del agente no hará posible una interpretación de su comportamiento como efectivamente expresivo de una falta de adopción del compromiso práctico que se habría seguido de un reconocimiento subjetivo de la norma como razón vinculante. Tal como Hälschner correctamente diera forma al problema, una expresión objetivada de la falta de reconocimiento de la norma por parte del agente no desempeña aquí una función meramente "evidencial"133, sino que es constitutiva de la falta personal capaz de sustentar una adscripción de responsabilidad a título de tentativa ${ }^{134}$.

Es recién desde este punto de vista que la distinción entre los conceptos de tentativa acabada y tentativa inacabada se vuelve pertinente. Pues el hecho de que el potencial autor haya plena o definitivamente ejecutado u omitido la acción que, bajo su representación, habría tenido que omitir o ejecutar para ajustar su comportamiento a la norma, resulta concluyentemente indicativo de su falta de reconocimiento subjetivo de la norma como razón vinculante. En contraste con ello, si el agente no llegó a ejecutar u omitir esa misma acción plena o definitivamente, es necesario contar con un ulterior indicador intrínseco -en oposición a un mero síntoma- de su actual déficit de reconocimiento subjetivo de la norma. En esto consiste la exigencia de la así llamada "resolución al hecho", en el sentido de que el reconocimiento de una tentativa inacabada solo puede tener lugar si el comportamiento del agente es indicativo de que este ya está resuelto a ejecutar u omitir la acción en cuestión, bajo las circunstancias que él mismo asume como efectivas ${ }^{135}$, mas sin que tal resolución necesite abarcar la ejemplificación de las respectivas propiedades fundantes-de-antinormatividad por el comportamiento en cuestión; respecto de esto último es suficiente que al agente pueda adscribirse la correspondiente creencia predictiva, exigida por el concepto de dolo (eventual). Notablemente, una exigencia enteramente equivalente aparece formulada, en la tradición del common law, en términos de una exigencia de "propósito específico" o "intención específica", cuya aparente equivocidad se disipa, empero, cuando la misma es disociada de la exigencia general de alguna forma de estado mental cuya adscripción fundamente el mens rea del delito correspondiente ${ }^{136}$.

Un segundo problema susceptible de clarificación, justamente sobre la base de la correcta caracterización de la creencia predictiva capaz de fundamentar la falta personal que

\footnotetext{
132 Aun cuando con otro propósito, una distinción muy próxima a esta es introducida por Mele (2012) pp. 391 ss., 397 s.

133 Tal como ello es sostenido por YAFFE (2010) pp. 215 ss.

134 HälsChner (1881) 342-343. Véase también Duff (1996) pp. 313 ss.; Duff (2012) pp. 412 ss. Al respecto también HART (1981) pp. 162 ss.

135 Hruschka (1999) pp. 242 ss. Véase también Jakobs (1991) 25/29-35.

136 Robinson (1997) pp. 131, 157 ss.; CAhill (2012) pp. 754 s.
} 
legitime la corriente adscripción de responsabilidad, concierne a la demarcación de la así llamada "tentativa inidónea" frente a la así (mal) llamada "tentativa irreal" y la (asimismo mal) llamada "tentativa supersticiosa" ${ }^{137}$, cuestión que en la tradición del common law remite a la pregunta por el estatus de los casos de "imposibilidad fáctica inherente"138.

El problema encuentra una vía de solución en el método previamente reseñado para determinar si es posible adscribir una creencia mínimamente suficiente para una imputación a título de dolo eventual. Ese método exige identificar síndromes de riesgo estandarizados, los cuales pueden servir como indicadores (derrotables) de la existencia de la respectiva creencia predictiva. Así, tal creencia puede ser adscrita al agente si se comprueba -bajo el estándar de prueba que resulte aplicable- que el agente tuvo por verdadero que se daban las circunstancias constitutivas del correspondiente síndrome de riesgo, con independencia de que efectivamente ello haya sido el caso.

Así, si una persona tiene por probable que, por la vía de acuchillar a un muñeco de cera, ella habrá de matar a su pretendida víctima -caso en el cual se hablaría de una "tentativa supersticiosa"-, no será posible adscribir a aquella una creencia predictiva, fundante de la correspondiente falta personal, que pudiera sustentar la imputación de un homicidio tentado ${ }^{139}$. Pues la representación de la circunstancia consistente en estar acuchillando a un muñeco de cera no es la representación de un síndrome de riesgode-homicidio. Esto lleva aparejado, como es obvio, una muy sensible cualificación de la caracterización de la falta personal, consistente en la respectiva infracción de deber, como constituida por vía de imputación subjetiva. La naturaleza subjetiva de la falta personal descansa en el hecho de que tal falta se constituye sobre la base de algún conjunto de estados cognitivos, consistentes en actitudes proposicionales atribuibles al agente. Pero esto no significa que el nivel de descripción relevante del objeto (intencional) de esos mismos estados cognitivos haya de ser fijado por el agente mismo ${ }^{140}$. Es la respectiva regla de imputación la que define cuál de las descripciones verdaderas del contenido representacional del conjunto de creencias del agente es privilegiadamente seleccionada para fundamentar la eventual atribución de responsabilidad jurídico-penal.

Last but not least, una tercera pregunta que puede ser esclarecida, a partir de la concepción aquí delineada, es si puede haber tal cosa como una tentativa imprudente. La

\footnotetext{
137 Se trata de designaciones equívocas, puesto que a las formas de comportamiento así etiquetadas se niega, por principio, "carácter de tentativa”. Véase al respecto AlWART (1982) pp. 201 ss., favoreciendo la comprensión de la segunda categoría como una subvariante de la primera; coincidentemente Moreno-Torres (1999) pp. 343 ss. La existencia de una relación de heterogeneidad (o mutua exclusión) de ambas categorías es afirmada por SANCINETTI (1995) pp. 181 ss., quien propone asociar la primera a "la aplicación de una regla de experiencia totalmente distorsionada" por parte del agente, en tanto que la segunda al reconocimiento del "carácter mágico de su comportamiento".

138 Véase Duff (1996) pp. 76 ss., 206 ss., 219 ss.; YAFFE (2010) pp. 237 ss.

139 Véase Duff (1996) p. 84.

140 En este contexto, "intencional" no significa "con una intención”, en el sentido ordinario del término, sino que designa, más bien, una propiedad distintiva de determinados estados mentales, consistente en su cualidad de ser "acerca-de-algo" (about-ness), esto es, en el hecho de que esos estados se refieren a algo que está más allá de ellos, con total independencia de si este "objeto intencional" efectivamente existe o no. Véase SEARLE (1983) pp. 1 ss.; SEARLE (2004) pp. 19 s., 112 ss.
} 
respuesta es negativa ${ }^{141}$. La imprudencia tiene que ser entendida como una estructura de imputación extraordinaria - y en tal medida: secundaria- frente al dolo, consistente en la falta de adopción de una medida de precaución a través de la cual el agente habría podido asegurar, de manera exigible, su capacidad situacional de omitir o ejecutar intencionalmente la acción cuya omisión o ejecución habría sido necesaria para ajustar su comportamiento a la norma ${ }^{142}$. Sin embargo, la concreta medida de precaución cuya adopción era en tal medida esperable del agente no puede ser propiamente determinada sin una referencia a la descripción normativamente relevante de la acción que el agente en efecto no fue capaz de omitir o ejecutar intencionalmente. Y esta descripción es la que especifica las propiedades que harían de tal acción una instancia del tipo de acción sometido a la norma de prohibición o de requerimiento, según se trate.

Como Moore acertadamente observa, el punto crucial aquí es que "in cases of mere negligence there is no description of some action A (that morality makes wrong) that is object of the actor's beliefs" 143 . Por ello, y como lo advirtiera ya Hälschner ${ }^{144}$, si no se ve objetivamente satisfecha la descripción que especifica el respectivo género de comportamiento antinormativo no es posible determinar la concreta medida de precaución que el agente habría tenido que adoptar para asegurar su capacidad de omitir o ejecutar la acción en una situación en la cual la norma respectiva habría podido fundamentar un deber de omitir o ejecutar esa misma acción. Esta es la razón por la cual, qua estructura de imputación sometida al principio de culpabilidad, la imprudencia solo es compatible con la consumación.

\section{BIBLIOGRAFÍA CITADA}

AlCÁCER, Rafael (2000): La tentativa inidónea (Granada, Editorial Comares).

Alexander, Larry, y Kessler Ferzan, Kimberly (2009), Crime and Culpability. A Theory of Criminal Law (Cambridge y New York, Cambridge University Press).

Alwart, Heiner (1982): Strafwürdiges Versuchen (Berlín, Duncker \& Humblot).

Aswhorth, Ashworth (1988): "Criminal Attempts and the Role of Resulting Harm under the Code, and in the Common Law", Rutgers Law Journal, 19: pp. 725-772.

Austin, John Langshaw (1962): How to Do Things with Words (Cambridge Mass., Harvard University Press, segunda edición).

Baron, Sam, Copley-Coltheart, Richard, Majeed, Raamey y Miller, Kristie (2013): "What is a Negative Property?", Philosophy, 88: pp. 33-54.

Beling Ernst (1906): Die Lehre vom Verbrechen (Tubinga, J.C.B. Mohr, Paul Siebeck).

Beling, Ernst (1930): Die Lehre vom Tatbestand (Tubinga, J.C.B. Mohr, Paul Siebeck).

Bennett, Jonathan (1988): Events and Their Names (Oxford, Clarendon Press).

Berman, Mitch (2012): "Attempts, in Language and in Law", Jerusalem Review of Legal Studies, 6: pp. 1-19.

${ }_{141}$ Coincidentemente, aunque a partir de premisas solo parcialmente congruentes con las aquí asumidas, AlWART (1982) pp. 154 ss.

142 En detalle Mañalich (2015) pp. 15 ss., con referencias ulteriores.

143 MoOre (1997) p. 413.

144 HälsChner (1881) pp. 332 ss. Véase también KindHÄUser (1989) pp. 93 s. 
BInDING, Karl (1902): Lehrbuch des Deutschen Strafrechts. Besonderer Teil, tomo I (Léipzig, Wilhelm Engelmann, segunda edición).

BINDING, Karl (1918): Die Normen und ihre Übertretung III (Léipzig, Felix Meiner).

Binding, Karl (1922): Die Normen und ihre Übertretung I (Léipzig, Felix Meiner, cuarta edición).

Brandom, Robert (1994): Making it Explicit (Cambridge Mass., Harvard University Press).

Bratman, Michael (1999): Intention, Plans, and Practical Reason (Stanford, CSLI).

Brudner, Alan (2009): Punishment and Freedom (Oxford, Oxford University Press).

Bunge, Mario (1999): Buscar la filosofía en las ciencias sociales (México D.F., Madrid y Buenos Aires, Siglo XXI).

CaHill, Michael (2012): "Defining Inchoate Crime: An Incomplete Attempt", Ohio State Journal of Criminal Law, 9: pp. 751-759.

Carrara, Francesco (1956): Programa de Derecho Criminal. Parte General I (Bogotá, Editorial Temis).

DaHAN-Katz, Leora (2012): "Questioning the Normative Relevance of Philosophy of Action in Gideon Yaffe's Attempts", Jerusalem Review of Legal Studies, 6: pp. 36-50.

Dan-Cohen, Meir (2002): Harmful Thoughts (Princeton y Oxford, Princeton University Press).

Davidson, Donald (2001): Essays on Actions and Events (Oxford, Oxford University Press, segunda edición).

Dennett, Daniel (1969): Content and Consciousness (Londres y Nueva York, Routledge \& Kegan Paul).

Donnelly-Lazarov, Bebhinn (2015): A Philosophy of Criminal Attempts (Cambridge, Cambridge University Press).

Duff, Antony (1990): Intention, Agency \& Criminal Liability (Oxford y Cambridge Mass, Basil Blackwell).

Duff, Antony (1996): Criminal Attempts (Oxford, Clarendon Press).

Duff, Antony (2007): Answering for Crime (Oxford y Portland, Hart Publishing).

Duff, Antony (2012): "Guiding Commitments and Criminal Liability for Attempts", Criminal Law and Philosophy, 6: pp. 411-427.

EngISCH, Karl (2010): Einführung in das juristische Denken (Stuttgart: W. Kohlhammer, undécima edición).

Enoch, David (2012): "Comment on Yaffe's Attempts", Jerusalem Review of Legal Studies, 6: pp. 20-35.

Farré Trepat, Elena (2011): La tentativa de delito (Madrid, Montevideo y Buenos Aires, Edisofer y BdF, segunda edición).

Feinberg, Joel (2003): Problems at the Roots of Law (New York y Oxford, Oxford University Press).

FincKe, Martin (1975): Das Verhältnis des Allgemeinen zum Besonderen Teil des Strafrechts (Berlín, J. Schweitzer Verlag).

Fletcher, George (1998): Basic Concepts of Criminal Law (New York y Oxford, Oxford University Press).

Freund, Georg (1992): Erfolgsdelikt und Unterlassen (Colonia, Carl Heymanns Verlag). 
FrIsch, Wolfgang (1988): Tatbestandsmäßiges Verhalten und Zurechnung des Erfolgs (Heidelberg, C.F. Müller).

Goldman, Alvin (1970): A Theory of Human Action. (Engelwood Cliffs N.J., PrenticeHall).

Hälschner, Hugo (1881): Das Gemeine Deutsche Strafrecht, vol. I. (Bonn, Adolph Marcus).

Hart, H.L.A (1968): Punishment and Responsibility. (Oxford, Clarendon Press).

HART, H.L.A (1981): "The House of Lords on Attempting the Impossible", Oxford Journal of Legal Studies, 1: pp. 149-166.

Hart, H.L.A (1994): The Concept of Law (Oxford, Clarendon Press, segunda edición).

Heath, Peter (1971): "Trying and Attempting", Proceedings of the Aristotelian Society, Supplementary Volumes, 45: pp. 193-208.

HruschKa, Joachim (1999): "Das delictum perfectum zwischen Versuch und Vollendung", en Gössel, K.H. y Triffterer, O., Gedächtnis für Heinz Zipf. Heidelberg: C.F. Müller, pp. 235-253.

JAKOBS, Günther (1991): Strafrecht Allgemeiner Teil (Berlín: Walter de Gruyter).

Jiménez de AsúA, Luis (1985): Tratado de Derecho Penal VII (Buenos Aires, Losada, tercera edición).

KindHÄUSER, Urs (1980): Intentionale Handlung (Berlín, Duncker \& Humblot).

KindhäUser, Urs (1989): Gefährdung als Straftat (Fráncfort del Meno, Vittorio Klostermann).

KINDHÄUSER, Urs (2007): "Der subjektive Tatbestand im Verbrechensaufbau. Zugleich eine Kritik der Lehre von der objektiven Zurechnung”, Goltdammer's Archiv für Strafrecht, 2007: pp. 447-468.

Londoño, Fernando (2016): "Estudio sobre la punibilidad de la tentativa con dolo eventual en Chile. ¿Hacia una noción de tipo penal diferenciado para la tentativa?”, Revista de Ciencias Penales, 93, No 3: pp. 95-130.

MaIER, Thomas (2005): Die Objektivierung des Versuchsunrechts (Berlín, Duncker \& Humblot).

Malamud, Jaime (2008): Suerte, acción y responsabilidad: un ensayo sobre suerte, moralidad y castigo (Bogotá, Editorial Universidad del Rosario).

Mañalich, Juan Pablo (2006): "Bases para una teoría comparativa del hecho punible", Revista Jurídica de la Universidad de Puerto Rico, 75, No 2: pp. 561-695.

Mañalich, Juan Pablo (2009): Nötigung und Verantwortung (Baden-Baden, Nomos).

Mañalich, Juan Pablo (2011): "El delito como injusto culpable. Sobre la conexión funcional entre el dolo y la consciencia de la antijuridicidad", Revista de Derecho de la Universidad Austral de Chile, 24: pp. 87-115.

MaÑAlich, Juan Pablo (2013): "La exculpación como categoría del razonamiento práctico", InDret 1/2013: pp. 1-29, disponible en: http://www.indret.com/pdf/944.pdf.

Mañalich, Juan Pablo (2014a): Norma, causalidad y acción (Madrid, Barcelona, Buenos Aires y San Pablo, Marcial Pons).

Mañalich Juan Pablo (2014b): "Normas permisivas y deberes de tolerancia", Revista Chilena de Derecho 41, No 2: pp. 473-522. 
Mañalich, Juan Pablo (2015): "La imprudencia como estructura de imputación”, Revista de Ciencias Penales, XLII, No 3: pp. 13-36.

Mañalich, Juan Pablo (2017): "Responsabilidad, autoridad y democracia: una exploración crítica de la filosofía del derecho penal de Antony Duff”, de próxima publicación en Discusiones.

MaYer, Max-Ernst (1915): Der Allgemeine Teil des Deutschen Strafrechts (Heidelberg, Carl Winters Universitätsbuchhandlung).

Mele, Alfred (2012): "Crimes of Negligence: Attempting and Succeeding", Criminal Law and Philosophy, 6: pp. 387-398.

Molina, Fernando (2001): Antijuridicidad penal y sistema del delito (Barcelona, Bosch).

Moore, Michael (1993): Act and Crime (Oxford, Oxford University Press).

Moore, Michael (1997): Placing Blame (Oxford, Oxford University Press).

Moore, Michael (2011): "Intention as Marker of Moral Culpability and Legal Punishability", en Duff, R.A. y Green, S. (eds.), Philosophical Foundations of Criminal Law (Oxford y Nueva York, Oxford University Press) pp. 179-205.

Moore, Michael (2013): "Yaffe's Attempts", Legal Theory, 19: pp. 136-177.

Moreno-Torres, Ma Rosa (1999): Tentativa de delito y delito irreal (Valencia, Tirant lo Blanch).

Nagel, Thomas (1979): Mortal Questions (Cambridge, Cambridge University Press).

NovoA, Eduardo (1961): "Algunas consideraciones acerca de la tentativa", Revista de Ciencias Penales, XX, No 1 (3a época): pp. 3-32.

NowAKOWSKI, Friedrich (1951): "Zur Lehre von der Rechtswidrigkeit", Zeitschrift für die gesamte Strafrechtswissenschaft, 63: pp. 287-331.

Pardo, Michael y Paterson, Dennis (2013): Minds, Brains, and Law (Oxford y Nueva York: Oxford University Press).

PARFIT, Derek (2011): On What Matters I (Oxford y Nueva York, Oxford University Press).

Pérez BarberÁ, Gabriel (2010): El dolo eventual (Buenos Aires, Hammurabi).

Pippin, Robert (2008): Hegel's Practical Philosophy (Cambridge, Cambridge University Press).

Politoff, Sergio (1999): Los actos preparatorios del delito. Tentativa y frustración (Santiago, Editorial Jurídica de Chile).

Puppe, Ingeborg (1979): Idealkonkurrenz und Einzelverbrechen (Berlín, Duncker \& Humblot).

PupPE, Ingeborg (1991): "Der Vorstellungsinhalt des dolus eventualis", Zeitschrift für die gesamte Strafrechtswissenschaft, 103: pp. 1-42.

Puppe, Ingeborg (2011): Kleine Schule des juristischen Denkens (Gotinga, Vandenhoeck \& Ruprecht, segunda edición).

Ragués, Ramón (1999): El dolo y su prueba en el proceso penal (Barcelona, Bosch).

Raz, Joseph (1990): Practical Reason and Norms (Oxford, Oxford University Press, segunda edición).

Robinson, Paul (1997): Structure and Function in Criminal Law (Oxford, Clarendon Press). 
SancinetTi, Marcelo (1991): Teoría del delito y disvalor de acción (Buenos Aires, Hammurabi).

SancinetTi, Marcelo (1995): Fundamentación subjetiva del ilícito y desistimiento de la tentativa (Bogotá, Temis).

SCAnlon, Thomas (2008): Moral Dimensions (Cambridge Mass. y Londres, Belknap Press).

SEARLE, John (1983): Intentionality (Cambridge, Cambridge University Press).

Searle, John (2004): Mind. A Brief Introduction (Oxford y Nueva York, Oxford University Press).

Sellars, Wilfrid (1997): Empiricism and the Philosophy of Mind (Cambridge Mass. y Londres, Harvard University Press).

Spendel, Günter (1953): "Zur Notwendigkeit des Objektivismus im Strafrecht”, Zeitschrift für die gesamte Strafrechtswissenschaft, 65: pp. 519-538.

STARK, Findlay (2016): Culpable Carelessness (Cambridge, Cambridge University Press).

StUCKenberG, Carl-Friedrich (2007): Vorstudien zu Vorsatz und Irrtum im Völkerstrafrecht (Berlín, Walter de Gruyter).

TARski, Alfred (1944): “The Semantic Conception of Truth", Philosophy and Phenomenological Research, 4, No 3: pp. 341-376.

Thomson, Judith Jarvis (1990): The Realm of Rights (Cambridge Mass. y Londres, Harvard University Press).

Toulmin, Stephen (2003): The Uses of Argument (Cambridge, Cambridge University Press, updated edition).

Von Wright, Georg Henrik (1963a): Norm and Action (Londres, Routledge \& Kegan Paul).

Von Wright, Georg Henrik (1963b): The Varieties of Goodness (Londres, Routledge \& Kegan Paul).

VON WRIGHT, Georg Henrik (1971): Explanation and Understanding (Londres, Routledge \& Kegan Paul).

Von Wright, Georg Henrik (1983): Practical Reason. Philosophical Papers I (Oxford, Basil Blackwell).

Wachter, Matthias (2015): Das Unrecht der versuchten Tat (Friburgo, Mohr Siebeck).

Williams, Bernard (1981): Moral Luck (Cambridge, Cambridge University Press).

Winch, Peter (1971): “Trying and Attempting”, Proceedings of the Aristotelian Society, Supplementary Volumes, 45: pp. 209-227.

Yaffe, Gideon (2010): Attempts in the Philosophy of Action and in the Criminal Law (Oxford, Oxford University Press).

Yaffe, Gideon (2012a): "More Attempts: A Reply to Duff, Husak, Mele and Walen", Criminal Law and Philosophy, 6: pp. 429-444.

YAfFE, Gideon (2012b): “The Legal Importance of Trying: Reply to Enoch, Dahan-Katz, and Berman", Jerusalem Review of Legal Studies, 6: pp. 51-78.

Yaffe, Gideon (2013): “Trying to Defend Attempts: Replies to Bratman, Brink, Alexander, and Moore", Legal Theory, 19: pp. 178-215.

ZangWILl, Nick (2011): "Negative Properties", Noûs, 45(3): pp. 528-556. 